\title{
Liberty, Security, and Accountability: The Rise and Fall of Illiberal Democracies
}

\author{
Gabriele Gratton and Barton E. Lee*
}

September 29, 2020

\begin{abstract}
We study a model of the rise and fall of illiberal democracies. Voters value both liberty and security. In times of crisis, voters may prefer to elect an illiberal government that, by violating constitutional constraints, offers greater security but less liberty. However, violating these constraints allows the government to manipulate information, in turn reducing electoral accountability. We show how elements of liberal constitutions induce voters to elect illiberal governments that remain in power for inefficiently long-including forever. We derive insights into what makes constitutions stable against the rise of illiberal governments. We extend the model to allow for illiberal governments to overcome checks and balances and become autocracies. We briefly discuss the empirical relevance of our theoretical framework.
\end{abstract}

*School of Economics, UNSW Business School, UNSW Sydney. Email: g.gratton@unsw.edu.au; barton.e.lee@gmail.com. We are grateful to Steve Callander, Juan Carlos Carbajal, Richard Holden, Anton Kolotilin, Federico Masera, Carlo Prato, and all participants at the UNSW Political Economy Coffee. Chris Burnitt and Jonathan Nathan provided useful research assistance. 


\section{Introduction}

Voters value both liberty and security. ${ }^{1}$ They value the fundamental tenets of the liberal state: individual freedoms and rights, the rule of law, and the protection of underrepresented minorities. ${ }^{2}$ They also value the security offered by the state: protection from violent threats, adverse economic shocks, and expropriation.

Liberal constitutions place formal constraints on executives with the aim of guaranteeing liberty. Governments are forbidden from enforcing laws that courts have ruled infringe constitutionally protected rights. They are also often legally forbidden from using their powers to gain an electoral advantage. For example, governments may not recruit state employees for electoral campaigns, ${ }^{3}$ nor influence bureaucrats or media to censor unfavorable information. However, executives have de facto substantial leeway beyond these legal constraints-often limited only by their accountability to the voters. ${ }^{4}$

Democracies around the world are increasingly electing governments that operate beyond the liberal constraints of their constitutions (Foa and Mounk, 2017; Svolik, 2019). The governments of Jarosław Kaczyński in Poland, Donald Trump in the United States, Viktor Orbán in Hungary, and Recep Tayyip Erdoğan in Turkey, have infringed (albeit to different extents) fundamental liberal rights: freedom of speech and association, civil rights, and the rule of law (Huq and Ginsburg, 2018; Luo and Przeworski, 2019). Yet, they all remained formally accountable to the electorate and seldom, if at all, resorted to coercive means of repression. ${ }^{5}$ These illiberal democracies rose to power with significant

\footnotetext{
${ }^{1}$ The adage, commonly attributed to Benjamin Franklin, that "those who give up liberty for security deserve neither" is popularly used to remark that a true supporter of liberal democracy should not be willing to tradeoff liberty for greater individual benefits-though Franklin's original meaning may have been misinterpreted (Wittes, 2011).

${ }^{2}$ Graham and Svolik (2020) and Svolik (2020) show experimentally that voters value democratic norms that protect minorities but are willing to trade them off for more favorable economic policies-in the language we use in this paper, for more security.

${ }^{3}$ To this effect, in the U.S., the Hatch Act of 1939 precludes most federal employees from taking part in political campaigns.

${ }^{4}$ Posner and Vermeule (2011) argue that elections, parties, and political culture "constrain the executive far more than do legal rules created by Congress or the Courts; and although politics hardly guarantees that the executive will always act in the public interest, politics at least limits the scope for executive abuses."

${ }^{5}$ These governments did not overthrow their democratic constitutions and violated liberal rights in ways that ostensibly observed the letter (if not the spirit) of their respective constitutions (Howell, Shepsle and Wolton, 2019; Huq and Ginsburg, 2018). However, commentators and scholars alike often worry that these illiberal democracies may be a step towards autocracy, perhaps following a similar pattern to that of fascist regimes in the 1930s. We return to this possible dynamic later in the paper.
} 
popular support and some remained sufficiently popular to ensure their own reelection. ${ }^{6}$ Illiberal democracies offer to voters something they may prefer to liberty: security. Illiberal leaders boast about their results on economic performance, quality public services, and protection against violent and economic threats from within and outside the country. ${ }^{7}$ In their rhetoric, their disrespect for formal liberties is exactly what enables them to deliver on these promises. ${ }^{8}$ In fact, deviating from liberal norms may allow them to more effectively repress domestic terrorists, quash corruption, or offer to the median voter favorable economic treatment compared to what is offered to minorities. ${ }^{9}$ Therefore, when voters receive information that suggests a greater need for security, they may prefer an illiberal government to one that is committed to operate within the limits of the constitution. Yet, voters should also reason that governments that operate beyond the rule of law will inevitably (ab)use their constitutional powers to reduce their electoral accountability. In fact, illiberal democracies routinely manipulate information. ${ }^{10}$ For example, they engage the state bureaucracy to produce favorable or misleading information, or harass bureaucrats who produce unfavorable reports. ${ }^{11}$ They co-opt media sharehold-

${ }^{6} \mathrm{Guriev}$ and Treisman (2020a) document long-lasting support for autocracies and illiberal democracies. In 2015, Kaczyński's party, Law and Justice, was the first party to win a majority of seats in the Polish parliament since the fall of communism and their vote share increased in the subsequent 2019 election. In 2010, Orbán's Fidesz won an outright majority of the vote share and continued to remain the first party in Hungary for two further general elections with a vote share of $49.27 \%$ in 2018 . Singapore may represent an example of illiberal democracy that maintains popular support for several decades; as reported in Guriev and Treisman (2020a), "in Singapore in 2009, 98 percent of respondents told Gallup they thought the government of Prime Minister Lee Hsien Loong was doing a good job."

${ }^{7}$ Guriev and Treisman (2019) argue that contemporary autocrats and illiberal leaders focus on economic performance rather than repression when addressing the general public.

${ }^{8}$ In a speech in 2014, citing Singapore, Russia, and Turkey as examples, Viktor Orbán famously remarked that "there is a race underway to find the method of community organization, the state, which is most capable of making a nation and a community internationally competitive", adding that "systems that are not [...] liberal democracies and perhaps not even democracies, can nevertheless make their nations successful" and that "liberal democracy will probably be incapable of maintaining their global competitiveness in the upcoming decades" (Orbán, 2014).

${ }^{9}$ There is a longstanding theory within economics and political science that autocratic governments produce higher economic growth. Recently, Collier (2010) and Krieckhaus (2006) showed that, in some instances, a more liberal democracy can constrain economic growth. Furthermore, leaders facing less constraints on their power have been shown to have greater influence on a country's economic performance and policies (Jones and Olken, 2005). Cheibub, Hong and Przeworski (2020) document how more solid democracies were significantly slower in limiting individual freedoms to stop the spread of the COVID-19 pandemic. The offer of protection against the threat of socialism or elite capture was also at the basis of the rhetoric of fascist regimes in the 1930s (Acemoglu, Feo, Luca and Russo, 2020).

${ }^{10} \mathrm{Guriev}$ and Treisman $(2019,2020 \mathrm{~b})$ document that many 21 st Century autocracies and illiberal democracies (what they call "informational autocracies") maintain power through subtle control of information, rather than through violent repression of the oppositions.

${ }^{11}$ For example, in September 2020, Brian Murphy, former head of the Department of Homeland Security's intelligence division, filed a whistleblower complaint accusing the acting secretary of the department of ordering to suppress reports that "made the president look bad" (Department of Homeland Security Office of Inspector General, 2020). 
ers into the government, or threaten media outlets with lawsuits or the withholding of state funding and advertising. ${ }^{12}$ Such information manipulation is likely to reduce effective electoral accountability, perhaps explaining the enduring electoral success of some illiberal democracies. ${ }^{13}$

Much attention has been given to the rise of illiberal democracies (recent examples include Berman, 2019; Grillo and Prato, 2020; Luo and Przeworski, 2019; Nalepa et al., 2020; Rosenbluth and Shapiro, 2018; Svolik, 2020). More puzzling is that while they sometimes stick, illiberal democracies also frequently fall. Why do some illiberal democracies prove more resilient than others? How do voters who ostensibly support illiberal leaders also return to prefer liberal democracy?

In this paper we offer a theory of the rise and fall of illiberal democracies. We use this theory to draw insights into what makes some liberal constitutions stable against the danger of illiberal democracy. We show how this depends on the median voter's values of liberty and security, the constitutional constraints limiting liberal executives, as well as on the transparency of institutions and media that provide information to voters in liberal democracies. We also extend our theory to allow for the possibility of a total executive takeover by which illiberal democracies may overcome constitutional checks and balances and become autocracies. Finally, we discuss the empirical relevance of our theoretical framework.

We study a benchmark model with an infinitely lived and forward looking voter. We interpret this voter as a median voter who values both liberty and security. ${ }^{14}$ In each period the voter chooses whether to elect a liberal or an illiberal government. Liberal governments are committed to respect the constitutional constraints on the executive, therefore offering to the voter greater liberty but less security. In each period, the cost of security depends on whether there is a threat to the voter's welfare that cannot be neutralized without resorting to means forbidden by the constraints the constitution places on the executive. More transparent institutions and media offer more precise information about each period's threat to the voter. Thus, depending on the features of the constitu-

\footnotetext{
${ }^{12}$ See Guriev and Treisman (2019), p. 118, for a review of such soft censorship strategies in Lee Kuan Yew's Singapore, Orbán's Hungary, Putin's Russia, and Fujimori's Peru; Szeidl and Szucs (2020) focuses on the Hungarian case. Using a measure of government transparency on economic indicators, Hollyer, Rosendorff and Vreeland (2014) document a sudden drop in transparency at the onset of illiberal democracies.

${ }^{13}$ Hollyer, Rosendorff and Vreeland (2015) show empirically that autocratic regimes that provide less information to their citizens are more stable. Edmond (2013) argues that information manipulation can be an effective tool in protecting regimes against uprisings. Guriev and Treisman (2020b) offer a theory of how autocratic regimes can co-opt the media and elites into manipulating information observed by citizens.

${ }^{14}$ In Section 6 we extend the model to allow for a continuum of voters with differing values of liberty and security. In this case, the pivotal voter is the one with the median relative value of liberty.
} 
tion and the observed information, in each period the voter may prefer either a liberal or an illiberal government, optimally trading off liberty and security. However, the voter knows that electing an illiberal government comes with an endogenously determined accountability cost: since the illiberal government does not respect the constitutional constraints on the executive, it can manipulate the information the voter observes about the following period's threat. We model the illiberal government's problem as one of optimal Bayesian persuasion (Kamenica and Gentzkow, 2011). The voter knows the choice of information manipulation - which we call a censorship policy-but can only indirectly infer the information she would have otherwise observed had she chosen a liberal government.

In equilibrium, the parameters of the model determine which of four different regimes arises. At two extremes, the polity is either a stable liberal democracy with continuously liberal governments or a stable illiberal democracy with continuously illiberal governments. In both these cases, the choice of government is optimal for the voter given the uncensored information provided to her by institutions and media. However, the polity may also be an inefficient stable illiberal democracy. In this regime, the voter eventually resorts to electing an illiberal government that remains in power forever by censoring all relevant information for the voter. Absent censorship, the voter would actually find it optimal to cycle between liberal and illiberal governments. We show that an inefficient stable illiberal democracy arises only if the expected cost of security under full censorship is greater than the sum of the value of liberty and the discounted maximal accountability cost of illiberalism. When this condition fails, illiberal governments cannot ensure their own reelection by simply censoring all information. However, if anything, this increases the appeal for the voter of an illiberal government, as this now comes with a smaller accountability cost. This gives rise to a cycling liberal-illiberal democracy in which liberal and illiberal governments alternate, but illiberal governments remain in power for longer than would be optimal for the voter.

In our model, the voter elects illiberal governments during crises that increase her expected cost of security. However, because the illiberal government manipulates information, the voter may be persuaded to reelect the government even if the crisis has passed. We show how the probability that an illiberal government rises from a liberal democracy depends on the amount of constraints on the executive, the voter's value of liberty, and the transparency of institutions and media. An immediate implication is that excessive constraints on the executive, which render liberal governments ineffective, are more likely to induce voters to elect an illiberal government. This result resonates with the literature suggesting that constitutional reforms that strengthen the executive's power are needed to safeguard liberal democracies (e.g., Howell and Moe, 2020). We add to this 
that technological changes that increase transparency may exacerbate this perverse effect of excessive constraints on the government and that, if anything, greater limits on the action of governments should be accompanied by greater ability to control information leaks, whistle-blowers, and voters' access to information in general. Vice versa, when information leaks are unavoidable, liberal stability can only be guaranteed by constitutions that place fewer constraints on the executive.

We also characterize the optimal amount of censorship of illiberal governments and show how it depends on the voter's values of liberty and security, the constraints on the executive, and the transparency of liberal institutions and media. The latter affects censorship through a persuasion effect and an accountability effect. By the persuasion effect, more transparent liberal institutions induce the illiberal government to censor more; by the accountability effect, they induce them to censor less. The persuasion effect dominates when the constitution has very few constraints on the executive; otherwise, the accountability effect dominates. These parameters also affect the likelihood that an illiberal democracy falls, returning the country to liberalism, when the illiberal government's censorship fails to conceal to the voter that the crisis has in fact passed. Again, the effect of more transparent liberal institutions depends on other features of the constitution, and can even be non-monotonic. We argue that these results help making sense of the empirical connection between transparency and the reelection probability of illiberal governments (Hollyer, Rosendorff and Vreeland, 2011, 2015).

In Section 6 we study the welfare implications of the design of stable liberal constitutions under a set of natural constraints-for example, that more liberty can only be achieved with greater constraints on the executive. Furthermore, we show that while more transparency is always favored by the median voter, it may harm every voter with a higher relative value of liberty-therefore potentially reducing aggregate welfare.

In Section 7 we extend our model in several realistic directions. First, we observe that illiberal leaders may exacerbate the voters' need for security, for example by taking more aggressive diplomatic stances or refusing negotiations with separatist groups. ${ }^{15} \mathrm{We}$ therefore allow the illiberal government to manipulate the voter's value of security once in power. Similarly, we observe that illiberal governments may sometimes be able to build the ability to overthrow the democratic constitution and dispense of electoral accountability altogether. In both cases, the government becomes a de facto autocracy that remains in power forever. Both processes are more likely to be set in motion when checks

\footnotetext{
${ }^{15}$ For example, Felshtinsky and Pribylovskyr (2008) and Satter (2003) argue that Vladimir Putin's conduct of the Chechen wars, and likely the Moscow bombings attributed to Chechen separatists, were orchestrated to generate popular support for a strong leader with knowledge and experience of the secret services.
} 
and balances preventing total executive takeover are weaker. We show that in the long-run this gives rise to only two possible regimes: stable liberal democracies and autocracies. When the probability that the government can build an autocracy is greater, non-stable illiberal democracies become autocracies faster. However, because the voter anticipates this risk, more constitutions induce stable liberal democracies (in fact, so much that some stable liberal democracies are inefficient from the point of view of the voter). Our results suggest that stronger checks and balances aimed at preventing total executive takeover, while slowing down this process, may actually induce voters to elect an illiberal government with greater probability-ultimately choosing the path to autocracy. ${ }^{16}$ Finally, we discuss some realistic long-term implications of censorship on the probability of the rise and fall of illiberal democracies.

As we discuss in Section 8, our theoretical framework helps make sense of individual and aggregate phenomena in the real world. We show that within consolidated democracies, individuals' fears of domestic and foreign threats correlate with less support for liberalism: more worried voters believe that the protection of civil rights is less important and that it would be better to have a strong executive who does not need to bother with parliament. We argue that the data are consistent with the view we propose in this paper that such individual preferences for illiberalism respond to the amount of constraints on the executive and may have consequences for the action of governments.

Related literature. Scholars have long wondered why and when illiberal leaders and governments are voted in by voters. The traditional view of democracy, from Montesquieu to Fearon, maintains that attempts to consolidate power from within a democratic constitution would be blocked by the voters. ${ }^{17}$ Besley and Persson (2019) argue that there is a natural complementarity between democratic values and institutions, creating persistence. This view has been recently challenged by the rise of populist, illiberal candidates even in consolidated democracies (Graham and Svolik, 2020; Luo and Przeworski, 2019). Foa and Mounk (2016) and Mounk (2018) argue that protracted dissatisfaction with the economic performance of liberal democracies has led voters to prefer more effective illiberal governments. Yet voters also value individual liberties, civil rights, and the rule of law (Graham and Svolik, 2020; Svolik, 2020). As a result, prevalent theories on the rise of illiberal democracies rely on factors that may make liberty less salient than economic

\footnotetext{
${ }^{16}$ Aghion, Alesina and Trebbi (2004) and Gratton and Morelli (2020) highlight different mechanisms through which excessive checks and balances may reduce voter welfare.

${ }^{17}$ In The Spirit of Law (1949 [1750]), Montesquieu famously argues that if a power were to succeed in violating the constitution, there would be a revolution reestablishing the rule of law. Fearon (2011) shows that democracy may be self-enforcing because the convention of an electoral calendar provides a public signal for the voters to coordinate against a ruling faction that attempts to not hold or rig an election.
} 
performance, resolving the voters' tradeoff in favor of more effective, yet less liberal governments. Such factors include: political polarization (Nalepa, Vanberg and Chiopris, 2020; Svolik, 2020) and the weakening of traditional mass parties (Berman and Snegovaya, 2019; Rosenbluth and Shapiro, 2018). Our model captures this fundamental tradeoff between liberty and security, but by studying the choice of a forward-looking, infinitely lived voter, ${ }^{18}$ we are able to also capture another fundamental and dynamic aspect of illiberal democracies: the loss of electoral accountability. ${ }^{19}$ This allows us to understand how various constitutional and technological features interact in determining the rise, and-in contrast with previous literature-the fall of illiberal democracies. In particular, our model allows us to understand the role played by the transparency of the state bureaucracy and the media, informing a growing debate on the role of government transparency in the rise of illiberal politicians (Mounk, 2018; Mudde and Rovira Kaltwasser, 2017; Sgueo, 2018).

The distinction between liberal democracies, which protect civil right, and illiberal democracies that only have free and fair elections is also at the core of Mukand and Rodrik (2020) who argue that transitions from autocracy to democracy are more likely to deliver illiberal democracies when there exist non-income cleavages within a country or when the income cleavages is less deep.

We model the ruling of the illiberal government as a process of information manipulation à la Kamenica and Gentzkow (2011). We share this feature with Luo and Rozenas (2019) and Kolotilin, Mylovanov and Zapechelnyuk (2019).

Our theory of the rise and fall of illiberal democracies partially overlaps with theories that aim at explaining the demand for populism. Guiso, Herrera, Morelli and Sonno $(2019,2020)$ document how economic insecurity fueled the demand for protection from globalization and the rise of populist leaders in Europe. ${ }^{20}$ Guriev and Papaioannou (2020) review the literature on the rise of populism focusing on the role of both economic and cultural causes. Although illiberalism and populism sometimes overlap, "only a minority of strongmen are populists and only a minority of populists is a strongman [...] the authoritarian characteristic of the strongman is not inherent to populism" (Mudde and Rovira Kaltwasser, 2017) (see also Guriev and Papaioannou, 2020).

\footnotetext{
${ }^{18}$ One feature that distinguishes our model from those of Bernhardt, Krasa and Shadmehr (2019) and Sachs (1989) is that our voter's choice for an illiberal government is not due to her shortsightedness.

${ }^{19}$ Grillo and Prato (2020) propose a different explanation for the dynamics of support for illiberalism that relies on voters' reference-dependent preferences.

${ }^{20}$ See also Anelli, Colantone and Stanig (2019); Autor, Dorn, Hanson and Majlesi (2020); Colantone and Stanig $(2018,2019)$.
} 


\section{The model}

We study a model with an infinitely-lived and forward-looking voter. This voter values both liberty and security. Liberty is meant to include the respect of individual rights of all citizens, as well as the protection of minorities. Security is meant to capture the government's protection of the majority's economic interests from external and internal threats. In Section 6 we extend the model to allow for a continuum of voters with differing values of liberty and security. In this case, the pivotal voter is the one with the median relative value of liberty. Therefore, the single voter in our benchmark model should be interpreted as representing this median voter.

In each period, the voter chooses whether to elect a liberal or an illiberal government. A liberal government comes with a cost of security for the voter that depends on the realization of a stochastic threat and on the stringency of the liberal constraints on the executive. An illiberal government insures the voter against this threat but comes at a liberty cost. The information available to the voter about the threat depends on the previous period's government. If the voter elected a liberal government, then she observes a signal about the next period's threat. The precision of this signal depends on the quality and transparency of the institutions of control on the executive: legislative oversight, independent judiciary, and free and competitive media. If the voter elected an illiberal government, then the illiberal government can manipulate the institutions of control so that the signal observed by the voter is a garbled version of the signal she would otherwise observe under a liberal government. The voter can observe the manipulation chosen by the illiberal government but can only indirectly infer what signal she may have received if she had chosen a liberal government instead. We call this information manipulation a censorship policy, but our model is more general in that it encompasses any mapping of the underlying signal of the state to a distribution of messages observed by the voter. The objective of an illiberal government is to remain in power as long as possible. If the voter does not reelect an incumbent illiberal government, we assume that the fallen illiberal government ceases to exist; a new illiberal government is generated if and when the voter chooses to elect an illiberal government again.

\subsection{Setup}

A forward-looking voter lives for infinitely many periods $t \in\{1,2, \ldots\}$. In each period $t$ the voter chooses the period- $t$ government $g_{t} \in\{i, \ell\}$. The voter's payoff in period $t, v\left(g_{t}, \theta_{t}\right)$, depends on the period- $t$ government, $g_{t}$, and a 
period-specific i.i.d. state, $\theta_{t} \in\{0,1\}$ :

$$
v\left(g_{t}, \theta_{t}\right)= \begin{cases}L-S \theta_{t} & \text { if } g_{t}=\ell ; \\ 0 & \text { if } g_{t}=i,\end{cases}
$$

where $L>0$ and $S>0$ are the value of liberty and value of security of the majority voter, respectively. Let $\pi$ be the probability that $\theta_{t}=1$. We interpret $\theta_{t}=1$ as the occurrence of a threat that the voters cannot be protected from unless the government resorts to means that are forbidden by the liberal constitution. Therefore, $\pi$ captures the liberal constraints on the executive. ${ }^{21}$

The government in period $t-1, g_{t-1} \in\{i, \ell\}$ with $g_{0}=\ell$, determines the information available to the voter at the beginning of period $t$. In particular, there exists a signal $s\left(\theta_{t}\right) \in\{0,1\}$ where $\operatorname{Pr}\left(s\left(\theta_{t}\right)=\theta_{t}\right)=q \in(1 / 2,1)$, representing the level of transparency of the liberal constitution and media. The government in period $t-1$ chooses a censorship policy from the signal $s\left(\theta_{t}\right)$ into a message $m_{t} \in\{0,1\}$ observed by the voter. More precisely, the government chooses the censorship policy $c_{t}:\{0,1\} \rightarrow[0,1]$, where $c_{t}(s)$ is the probability that the voter observes a period- $t$ message $m_{t}=1$ when $s\left(\theta_{t}\right)=s{ }^{22}$ Without loss of generality, we focus on censorship policies $c_{t}$ such that $c_{t}(1) \geq c_{t}(0)$. If $g_{t-1}=i$, an illiberal government strategically chooses the censorship policy. If $g_{t-1}=\ell$, then a liberal government chooses a censorship policy $c_{t}=c_{\ell}$ that fully reveals the signal $s\left(\theta_{t}\right)$, i.e., $c_{\ell}(s)=s$ for all $s \in\{0,1\}$.

In each period $t$, the timing of the events is as follows. First, $\theta_{t}$ is realized, and the voter observes $c_{t}$ and $m_{t}$. Second, the voter chooses whether to elect $g_{t}=i$ or $g_{t}=\ell$. Finally, the period- $t$ government, $g_{t}$, chooses the censorship policy, $c_{t+1}$.

An illiberal government elected for the first time in period $t$ receives a rent $R>0$ for period $t$ and each subsequent period until the first period $t^{\prime}>t: g_{t^{\prime}}=\ell$, at which point a liberal government is elected and the previous illiberal government is replaced by a new illiberal government. The voter and the illiberal government maximize their present discounted value of their payoffs and discount future periods with factor $\delta \in(0,1) .^{23}$

\footnotetext{
${ }^{21}$ Formally, in each period $t$, a new threat $\omega_{t}$ is drawn from a distribution $F$ over the set $\Omega \subseteq \mathbb{R}$. Let $U \subset \Omega$ be the set of unprotected threats if the government abides by the liberal constitution. Then $\theta_{t}=1$ corresponds to the event $\left\{\omega_{t} \in \Omega: \omega_{t} \in U\right\}$ and therefore $\pi=\operatorname{Pr}\left[\omega_{t} \in U\right]$.

${ }^{22}$ The binary structure of the government's message is without loss of generality given the governments' objectives (see below) and our focus on Markovian strategies.

${ }^{23}$ As we will show, the illiberal government's equilibrium strategy is independent of their own future payoff stream; hence, our results hold verbatim if the voter and illiberal government have discount factors $\delta_{V}=\delta$ and $\delta_{i} \in(0,1)$, respectively.
} 


\subsection{Constitutional design and welfare}

Within our framework, a constitution is a triplet $C:=(\pi, L, q)$ representing the constraints on the executive, the liberty granted to individuals and minorities, and the independence of institutions of control such as the judiciary and the media. Obviously, more constraints on the executive are needed to guarantee greater individual freedoms, so that $L=\mathcal{L}(\pi)$, and more independent bureaucracy and media, so that $q=\mathcal{Q}(\pi)$, where $\mathcal{L}$ and $\mathcal{Q}$ are both increasing functions. In Sections 3 to 5 we study our model taking each element of $C$ as independent. We then return to the connection between the three elements in Section 6 where we derive normative conclusions about the design of stable liberal democracies. We also note here that social welfare in our model is not fully captured by $v\left(g_{t}, \theta_{t}\right)$ as this only represents the utility of a majority (or median) voter who may trade off the liberty of a minority for a greater security of her own economic interests. In Section 6 we will return to this distinction and discuss how different members of a polity are differently affected by changes in the elements in its constitution, $C$.

\subsection{Equilibrium concept}

We characterize the perfect Bayesian equilibria (Fudenberg and Tirole, 1991) of our model in which the voter and the illiberal governments play pure Markovian strategies. Following the Bayesian persuasion literature (Kamenica and Gentzkow, 2011), we focus on equilibria in which the voter chooses an illiberal government whenever she is indifferent. Because $\theta_{t}$ is i.i.d., at time $t$, the voter's payoff relevant history is fully captured by $c_{t}$. Similarly, in period $t$, the illiberal government's payoff relevant history is fully captured by $g_{t}$. However, the illiberal government only takes action if $g_{t}=i$. Therefore, for any period $t$, the illiberal government's set of optimal censorship policies is time independent. For simplicity, we focus on equilibria where the illiberal government's choice of censorship policy is also time independent. ${ }^{24}$

A Markovian pure strategy for the voter is a mapping $g$ from the message observed by the voter, $m_{t}$, and the censorship policy, $c_{t}$, into the period- $t$ government, $g_{t}$. A Markovian pure strategy for the period- $t$ illiberal government is a choice $c$ of censorship policy, $c_{t+1}$. The voter's belief that $\theta_{t}=1$, denoted by $\mu_{t}$, is a mapping from the message observed by the voter, $m_{t}$, and the censorship policy, $c_{t}$, into a probability. A Markovian assessment is therefore a triple $\sigma=\left(g, c,\left\{\mu_{t}\right\}_{t=1}^{\infty}\right)$.

\footnotetext{
${ }^{24}$ This assumption does not affect the payoff-relevant properties of the equilibria, i.e., in each period $t$, the probability that an illiberal or liberal government is elected, conditional on the state, $\theta_{t}$.
} 
Definition 1 (Equilibrium.) An assessment $\sigma^{*}=\left(g^{*}, c^{*},\left\{\mu_{t}^{*}\right\}_{t=1}^{\infty}\right)$ is an equilibrium if, for each period $t$ :

(i) $g^{*}\left(m_{t}, c_{t}\right)=i$ if and only if

$$
L-\mu_{t}\left(m_{t}, c_{t}\right) S+\mathbb{E}\left[\sum_{\tilde{t}=t+1}^{\infty} \delta^{(\tilde{t}-t)} v\left(g_{\tilde{t}}, \theta_{\tilde{t}}\right) \mid g_{t}=\ell, \sigma^{*}\right] \leq \mathbb{E}\left[\sum_{\tilde{t}=t+1}^{\infty} \delta^{(\tilde{t}-t)} v\left(g_{\tilde{t}}, \theta_{\tilde{t}}\right) \mid g_{t}=i, \sigma^{*}\right]
$$

(ii) if $g_{t}=i$, then, for all censorship policies $c^{\prime}$,

$$
\mathbb{E}\left[\sum_{\tilde{t}=t+1}^{\infty} \delta^{\tilde{t}-t} R \mathcal{X}\left(\left\{g_{t^{\prime}}\right\}_{t+1}^{\tilde{t}}\right) \mid c_{t+1}=c^{*}, \sigma^{*}\right] \geq \mathbb{E}\left[\sum_{\tilde{t}=t+1}^{\infty} \delta^{\tilde{t}-t} R \mathcal{X}\left(\left\{g_{t^{\prime}}\right\}_{t+1}^{\tilde{t}}\right) \mid c_{t+1}=c^{\prime}, \sigma^{*}\right]
$$

where

$$
\mathcal{X}\left(\left\{g_{t^{\prime}}\right\}_{t+1}^{\tilde{t}}\right)= \begin{cases}1 & \text { if } g_{t^{\prime}}=i \text { for all } t^{\prime} \in\{t+1, \ldots, \tilde{t}\} \\ 0 & \text { otherwise }\end{cases}
$$

(iii) the voter's belief, $\mu_{t}\left(m_{t}, c_{t}\right)$, is derived using Bayes' rule, ${ }^{25}$ i.e.,

$$
\begin{aligned}
\mu_{t}\left(1, c_{t}\right)=\mu_{t}^{*}\left(1, c_{t}\right):=\operatorname{Pr} & {\left[\theta_{t}=1 \mid m_{t}=1, c_{t}\right] } \\
& =\frac{\pi\left[c_{t}(1) q+c_{t}(0)(1-q)\right]}{\pi\left[c_{t}(1) q+c_{t}(0)(1-q)\right]+(1-\pi)\left[c_{t}(1)(1-q)+c_{t}(0) q\right]},
\end{aligned}
$$

and

$$
\begin{aligned}
& \mu_{t}\left(0, c_{t}\right)=\mu_{t}^{*}\left(0, c_{t}\right):=\operatorname{Pr}\left[\theta_{t}=1 \mid m_{t}=0, c_{t}\right] \\
& =\frac{\pi\left[\left(1-c_{t}(1)\right) q+\left(1-c_{t}(0)\right)(1-q)\right]}{\pi\left[\left(1-c_{t}(1)\right) q+\left(1-c_{t}(0)\right)(1-q)\right]+(1-\pi)\left[\left(1-c_{t}(1)\right)(1-q)+\left(1-c_{t}(0)\right) q\right]}
\end{aligned}
$$

\section{All proofs appear in Appendix A.}

\footnotetext{
${ }^{25}$ By Property 1 of Definition 3.1 in Fudenberg and Tirole (1991), under any censorship policy, $c_{t}$ whether on or off the equilibrium path-and any message, $m_{t}$, that occurs with positive probability under $c_{t}$, the voter's belief must be derived using Bayes' rule from the prior belief that $\theta_{t}=1$, $\pi$, and the conditional probabilities, $c_{t}(0), c_{t}(1)$, and $q$.
} 


\section{The optimal voting and censorship strategies}

We begin by characterizing the voter's sequentially optimal strategy. In each period $t$, the voter observes a message, $m_{t}$, about $\theta_{t}$ and forms a belief about whether $\theta_{t}=1$. She then decides whether to elect an illiberal or a liberal government. In period $t$, electing a liberal government gives more liberty, $L$, but has an expected cost of security, $\mu_{t}\left(m_{t}, c_{t}\right) S$; electing an illiberal government always provides a payoff of zero. Therefore, absent dynamic considerations, the voter elects an illiberal government whenever the expected cost of security is greater than the value of liberty. However, electing an illiberal government comes at an additional dynamic cost for the voter. As an illiberal government can engage in censorship, electing an illiberal government today induces the voter to take a lessinformed choice of government tomorrow. This means that the expected continuation payoff of electing an illiberal government is smaller than the expected continuation payoff of electing a liberal government. Let

$$
V\left(g_{t}=\ell \mid \sigma\right):=\mathbb{E}\left[\sum_{\tilde{t}=t+1}^{\infty} \delta^{(\tilde{t}-t-1)} v\left(g_{\tilde{t}}, \theta_{\tilde{t}}\right) \mid g_{t}=\ell, \sigma\right]
$$

and

$$
V\left(g_{t}=i \mid \sigma\right):=\mathbb{E}\left[\sum_{\tilde{t}=t+1}^{\infty} \delta^{(\tilde{t}-t-1)} v\left(g_{\tilde{t}}, \theta_{\tilde{t}}\right) \mid g_{t}=i, \sigma\right]
$$

denote the expected continuation payoffs from electing a liberal and illiberal government, respectively. We define the accountability cost of illiberalism as

$$
A(\pi, q, L, S, \delta \mid \sigma):=V\left(g_{t}=\ell \mid \sigma\right)-V\left(g_{t}=i \mid \sigma\right)
$$

We will show that, in equilibrium, the accountability cost of illiberalism is decreasing in the informativeness of the censorship policy that the voter expects the illiberal government to choose. In particular, the maximum accountability cost of illiberalism is ${ }^{26}$

$$
\bar{A}(\pi, q, L, S, \delta):=\max \left\{0, \frac{\operatorname{Pr}\left[s\left(\theta_{t}\right)=0\right]}{1-\delta \operatorname{Pr}\left[s\left(\theta_{t}\right)=0\right]}\left(L-\operatorname{Pr}\left[\theta_{t}=1 \mid s\left(\theta_{t}\right)=0\right] S\right)\right\} .
$$

This maximal cost may be achieved if an illiberal government chooses a full censorship policy $c_{F}:=\{c: c(s)=\bar{c} \in[0,1] \forall s \in\{0,1\}\}$ and is able to ensure its own reelection.

\footnotetext{
${ }^{26}$ The maximum accountability cost of illiberalism equals zero whenever $L \leq \operatorname{Pr}\left[\theta_{t}=1 \mid s\left(\theta_{t}\right)=0\right] S$ because, even absent censorship, the voter always prefers to elect an illiberal government. Otherwise, the maximum cost is the expected payoff of choosing a liberal government for as long as $s\left(\theta_{t}\right)=0$ before then turning to illiberalism forever.
} 
Lemma 1 says that in equilibrium the voter elects an illiberal government if and only if the expected cost of security, $\mu_{t}\left(m_{t}, c_{t}\right) S$, is greater than the sum of the value of liberty, $L$, and the discounted accountability cost of illiberalism, $\delta A(\pi, q, L, S, \delta \mid \sigma)$.

Lemma 1 (The voter's optimal strategy.) In equilibrium, the voter elects the illiberal government in period $t$ if and only if

$$
\mu_{t}\left(m_{t}, c_{t}\right) S \geq L+\delta A\left(\pi, q, L, S, \delta \mid \sigma^{*}\right)
$$

We now turn to the illiberal government's problem. Lemma 2 establishes that the illiberal government's problem can be reduced to the problem of choosing the censorship policy that maximizes their probability of being reelected in the following period.

Lemma 2 (The illiberal government's problem.) In equilibrium, an illiberal government in period $t$ chooses a censorship policy $c_{t+1}=c^{*}$ that maximizes its reelection probability in period $t+1$.

In what follows, we characterize the illiberal government's optimal strategy. Lemma 3 says that, in equilibrium, illiberal governments are either indifferent between all censorship policies, or choose one of two types of censorship policies.

Lemma 3 (Optimal censorship.) In equilibrium, if an illiberal government is elected then it is either indifferent between all censorship policies or

1. if $\pi S \geq L+\delta \bar{A}(\pi, q, L, S, \delta)$, it chooses the full censorship policy, $c_{F}$, or any other censorship policy $c^{*}$ satisfying

$$
\mu_{t}^{*}\left(m_{t}, c^{*}\right) S \geq L+\delta \bar{A}(\pi, q, L, S, \delta) \quad \forall m_{t}
$$

2. Otherwise, it chooses $c^{*}(1)=1$ and $c^{*}(0)$ such that

$$
\mu_{t}^{*}\left(1, c^{*}\right) S=L+\delta A\left(\pi, q, L, S, \delta \mid \sigma^{*}\right)
$$

To understand Lemma 3, it is easier to focus on the censorship policies that always send signal $m_{t}=1$ whenever $s\left(\theta_{t}\right)=1$, i.e., $c(1)=1$. Point 1 of Lemma 3 considers the case when the voter reelects the illiberal government absent any information about the state (i.e., the equilibrium expected cost of security is greater than the value of liberty plus the discounted maximum accountability cost). In this case, it is optimal for the illiberal government to choose $c(0)=1$ - the full censorship policy. 
Otherwise, the illiberal government engages in partial censorship: it chooses $c(0)<1$. The precise probability is the one that induces a voter's belief $\mu_{t}^{*}(1, c)$ such that, upon observing message $m_{t}=1$, the voter is indifferent between electing a liberal or an illiberal government for the next period. The intuition behind the optimal partial censorship is akin to that in the Bayesian persuasion literature. ${ }^{27}$ Intuitively, greater censorship of unfavorable signals (a greater $c(0)$ ) increases the chances of reelection for the illiberal government up to the point at which the voter would correctly infer that, even upon observing message $m_{t}=1$, a liberal government is preferable.

However, there is a key difference between the role of censorship in our model and the one it plays in the Bayesian persuasion literature. In our model, greater censorship affects the voter's optimal choice through two distinct channels. First, more censorship directly increases the voter's expected cost of security of a liberal regime, because it increases her belief that protection from today's threats requires illiberal policies. Second, more censorship dynamically increases the accountability cost of illiberalism, because it increases the voter's value of a liberal system in which she can make a better-informed choice of government for the future. The tradeoff between these two effects drives the results in the following sections.

\section{Regime stability and cycles}

We now show that, depending on the constitution, $C=(\pi, L, q)$, the equilibrium behavior of our model gives rise to four different regimes. We begin with two extreme conditions under which two stable regimes arise. Proposition 1 says that if the value of liberty, $L$, is sufficiently large, while the cost of security, $S$, the constraints on the executive, $\pi$, as well as the transparency of the institutions, $q$, are sufficiently small, then a stable liberal democracy arises. In this regime, the voter always elects a liberal government, and this

\footnotetext{
${ }^{27} \mathrm{~A}$ censorship policy induces beliefs $\mu_{t}^{*}(1, c) \geq \pi \geq \mu_{t}^{*}(0, c)$. Notice that the probability of reelection is given by the probability that the voter observes a message $m_{t}$ inducing a belief that makes her at least indifferent between electing an illiberal and a liberal government. Thus, any policy $c^{\prime}$ such that $\mu_{t}^{*}\left(1, c^{\prime}\right)<$ $\mu_{t}^{*}\left(1, c^{*}\right)$ yields a probability of reelection equal to zero. Suppose that there existed an optimal partial censorship $c^{\prime}$ inducing belief $\mu_{t}^{*}\left(1, c^{\prime}\right)>\mu_{t}^{*}\left(1, c^{*}\right)$. I.e., upon observing message $m_{t}=1$ the voter strictly prefers to reelect the illiberal government. By Bayes' rule, this implies $c^{\prime}(0)<c^{*}(0)$. The probability of reelection under this policy is

$$
c^{\prime}(1)(q \pi+(1-q)(1-\pi))+c^{\prime}(0)((1-q) \pi+q(1-\pi))
$$
}

which is less than the probability of reelection under the optimal censorship $c^{*}$ :

$$
(q \pi+(1-q)(1-\pi))+c^{*}(0)((1-q) \pi+q(1-\pi)) .
$$


choice is optimal given the uncensored information offered by the constitution, $s\left(\theta_{t}\right)$.

Proposition 1 (Efficient stable liberal democracy.) Suppose $L>\mu_{t}^{*}\left(1, c_{\ell}\right) S$. In equilibrium, an illiberal government chooses any censorship mapping $c^{*}$; the voter elects an illiberal government if and only if $\mu_{t}^{*}\left(m_{t}, c_{t}\right) S \geq L$; and $g_{t}=\ell$ for all $t \geq 1$.

Intuitively, under this constitution, the liberal government offers valuable liberty and sufficient security to the voter, so that the voter always prefers to elect a liberal government. ${ }^{28}$

Proposition 2 says that if the value of liberty, $L$, is sufficiently small, while the cost of security, $S$, and the constraints on the executive, $\pi$, are sufficiently large, but the transparency of the institutions, $q$, is sufficiently small, then a stable illiberal democracy arises. In this regime, the voter always elects an illiberal government. Yet, her choice of government is optimal given the uncensored information offered by the constitution, $s\left(\theta_{t}\right)$.

Proposition 2 (Efficient stable illiberal democracy.) Suppose $L \leq \mu_{t}^{*}\left(0, c_{\ell}\right) S$. In equilibrium, an illiberal government chooses any censorship mapping $c^{*}$; the voter elects an illiberal government if and only if $\mu_{t}^{*}\left(m_{t}, c_{t}\right) S \geq L$; and $g_{t}=i$ for all $t \geq 1$.

Intuitively, under this constitution, the liberal government does not offer enough liberty nor security, and so the voter always prefers to elect an illiberal government. ${ }^{29}$

Proposition 3 identifies the conditions under which the voter eventually (but not necessarily at $t=1$ ) elects an illiberal government that remains in power forever. Crucially, absent censorship, the voter would find it optimal to cycle between liberal and illiberal governments. However, once she elects an illiberal government, the illiberal government chooses a full censorship policy ${ }^{30}$ and ensures its own reelection forever.

\section{Proposition 3 (Inefficient stable illiberal democracy.) Suppose}

$$
\mu_{t}^{*}\left(0, c_{\ell}\right) S<L \quad \text { and } \quad L \leq \pi S-\delta \bar{A}(\pi, q, L, S, \delta) .
$$

In equilibrium, under a liberal government, the voter elects an illiberal government if and only if $m_{t}=1$, which occurs with probability $\pi q+(1-\pi)(1-q)$. Once an illiberal government has been

\footnotetext{
${ }^{28}$ In this case, the accountability cost of illiberalism is zero because censorship cannot affect the voter's ability to choose the best government-the liberal government.

${ }^{29}$ In this case, the accountability cost of illiberalism is again zero because censorship cannot affect the voter's ability to choose the best government-the illiberal government.

${ }^{30}$ Technically speaking, in Proposition 3 the illiberal government chooses any censorship policy as in Point 1 of Lemma 3, which includes the full censorship policy.
} 
elected, it chooses the full censorship policy, $c_{F}$, or any other censorship policy $c^{*}$ satisfying

$$
\mu_{t}^{*}\left(m_{t}, c^{*}\right) S \geq L+\delta \bar{A}(\pi, q, L, S, \delta) \quad \forall m_{t}
$$

and the voter reelects the illiberal government with probability one.

Intuitively, under this constitution, the liberal government offers valuable liberty and security but, whenever the voter observes the period- $t$ message $m_{t}=1$, her expected cost of security is so high that she prefers to elect an illiberal government. She correctly anticipates that the decision to elect an illiberal government is forever: because of censorship she will continue to elect an illiberal government even though, absent censorship, she would optimally revert back to a liberal government with probability $\pi(1-q)+(1-\pi) q$ in each period. In fact, the voter correctly attributes to an illiberal government the maximal accountability cost, $\bar{A}$. Therefore, an inefficient stable illiberal democracy arises only if the expected cost of security under full censorship is greater than the sum of the value of liberty and the discounted maximal accountability cost:

$$
\pi S \geq L+\delta \bar{A}(\pi, q, L, S, \delta)
$$

When this condition is not satisfied, an illiberal government cannot ensure its own reelection. However, if anything, this increases the voter's propensity to elect an illiberal government in the first place because illiberalism now comes with a smaller accountability cost. Proposition 4 says that this gives rise to cycles of liberal and illiberal governments.

\section{Proposition 4 (Cycling liberal-illiberal democracy.) Suppose}

$$
\pi S-\delta \bar{A}(\pi, q, L, S, \delta)<L \quad \text { and } \quad L \leq \mu_{t}^{*}\left(1, c_{\ell}\right) S
$$

In any period $t$, the voter elects the illiberal government if and only if $m_{t}=1$, and the illiberal government engages in partial censorship, $c^{*}$. Therefore, if $g_{t-1}=\ell$, the voter elects the illiberal government with probability $\pi q+(1-\pi)(1-q)$, and if $g_{t-1}=i$, the illiberal government falls with probability $\left(1-c^{*}(0)\right)(\pi(1-q)+(1-\pi) q) \in(0,1)$.

In a cycling liberal-illiberal democracy, the voter elects an illiberal government whenever she observes $m_{t}=1$ and instead elects a liberal government whenever she observes $m_{t}=0$. Once elected, illiberal governments cannot afford to engage in full censorship. In fact, were they to fully censor all information, the voter would strictly prefer to immediately return to liberalism. Instead, in order to maximize their time in power, illiberal governments optimally engage in partial censorship (see Lemma 3). The voter elects 
the illiberal government knowing that this choice comes with a significant accountability cost. In fact, the optimal partial censorship ensures that the illiberal government remains in power for longer than it would be efficient: absent censorship, the voter would return to liberalism with strictly greater probability in each period the illiberal government is in power.

For any given value of security $S$, Propositions 1-4 allow for a mapping from constitutions $C=(\pi, L, q)$ into regimes. In particular, it is useful to normalize the value of liberty as the voter's relative value of liberty, $\bar{L}:=L / S$. Proposition 5 says that, as the voter's relative value of liberty increases, the regime transitions from an efficient stable illiberal democracy to an inefficient stable illiberal democracy to a cycling liberal-illiberal democracy, and then finally to an efficient stable liberal democracy.

Proposition 5 (A typology of regimes) There exist cutoffs $0<\underline{\kappa}(\pi, q)<\kappa(\pi, q ; \delta)<\bar{\kappa}(\pi, q)<$ 1 such that, in equilibrium, a constitution with

1. $\bar{L} \leq \underline{\kappa}(\pi, q)$ induces an efficient stable illiberal democracy;

2. $\bar{L} \in(\underline{\kappa}(\pi, q), \kappa(\pi, q ; \delta)]$ induces an inefficient stable illiberal democracy;

3. $\bar{L} \in(\kappa(\pi, q ; \delta), \bar{\kappa}(\pi, q)]$ induces a cycling liberal-illiberal democracy; and

4. $\bar{L}>\bar{\kappa}(\pi, q)$ induces an efficient stable liberal democracy.

The closed form of the cutoffs is given in Proposition 10 in Appendix A. Panels (a) and (b) in Figure 1 illustrate this regime typology in the $(\pi, \bar{L})$ and $(q, \bar{L})$ space, respectively. In each figure, the plotted curves from bottom to top correspond to $\underline{\kappa}(\pi, q), \kappa(\pi, q, \delta)$, and $\bar{\kappa}(\pi, q)$, respectively. The following section focuses on the stability of constitutions by studying how the different parameters in $C$ affect the rise and fall of illiberal democracies.

\section{The rise and fall of illiberal democracies}

This section studies how different elements of constitutions, such as the amount and stringency of the constraints on the executive, the amount of protection guaranteed to the minorities, and the transparency of the liberal institutions, affect the dynamics of evolution of democracies. In particular, we ask what favors the rise of illiberal democracies, how different elements of the constitution affect the type of censorship illiberal governments engage in, and, finally, what induces illiberal democracies to fall sooner, if at all. 


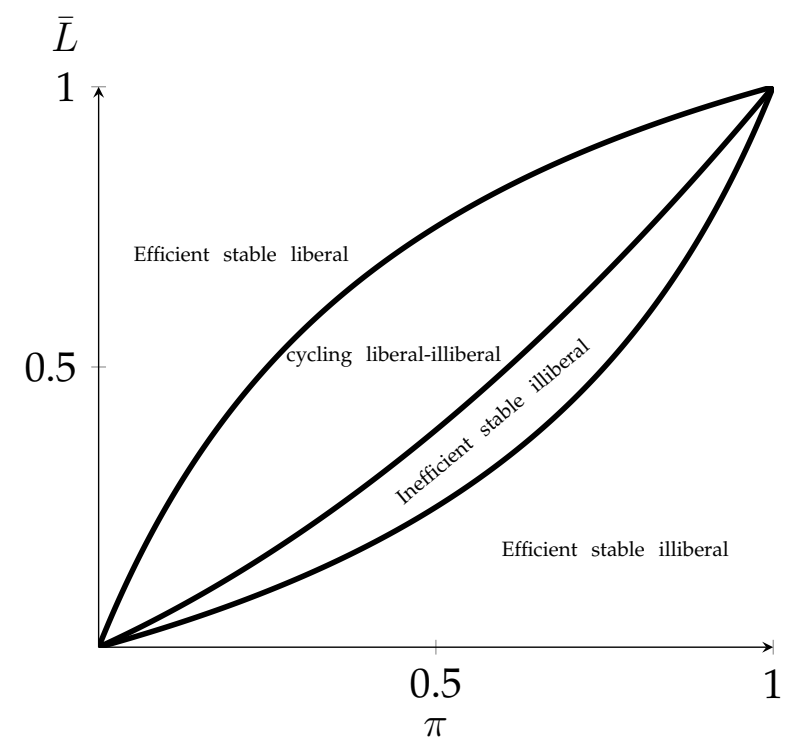

(a) $\delta=0.9$ and $q=0.75$.

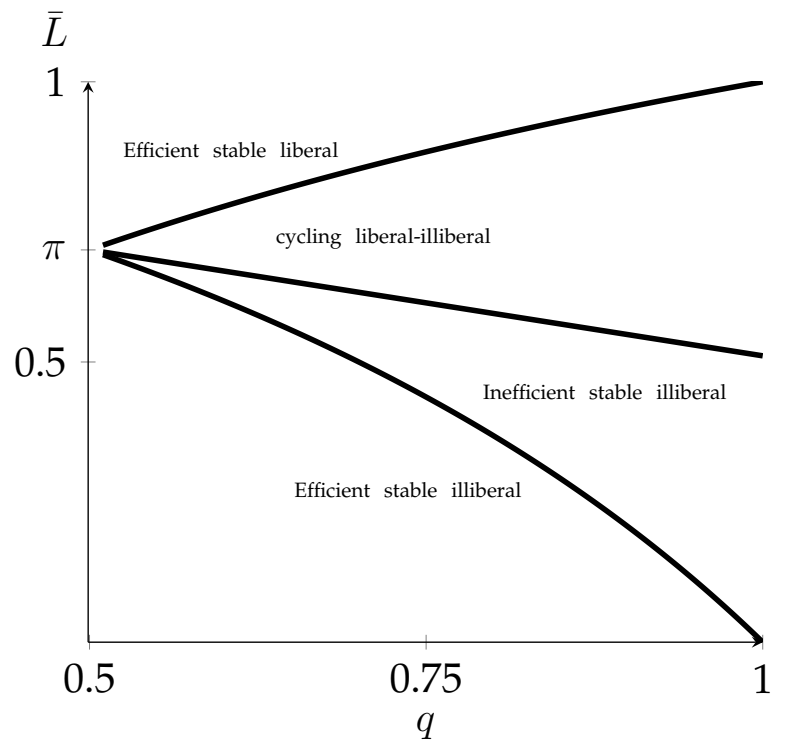

(b) $\delta=0.9$ and $\pi=0.7$.

Figure 1: Typology of regimes.

\subsection{The rise}

We begin by studying what causes the rise of illiberal democracies from a liberal government. An immediate implication of Proposition 1-4 is that, unless the constitution induces an efficient stable liberal or efficient stable illiberal democracy, an illiberal government is elected whenever the signal, $s\left(\theta_{t}\right)$, is equal to one. Intuitively, the voter resorts to an illiberal government when the expected cost of security of a liberal government becomes too high. When $s\left(\theta_{t}\right)=1$, the probability that the period-specific threat is one that the voters cannot be protected from by a liberal government (and therefore the expected cost of security) is high. This can be thought of as a crisis that increases the voter's perception that their welfare is under threat from terrorists, foreign powers, recessions, or a pandemic. The probability that such a crisis arises, as well as whether the voter is willing to elect an illiberal government during a crisis, depends on the different elements of the constitution.

Proposition 6 shows how the different elements of a constitution $C=(\pi, L, q)$ affect the probability that an illiberal government is elected following a liberal one. First, by Proposition 5, the probability that an illiberal government is elected equals 1 when the relative value of liberty is sufficiently small, and zero when it is sufficiently large. Otherwise, in inefficient stable illiberal democracies and in cycling democracies, an increase in the relative value of liberty induces voters to prefer a liberal government more, as the 
value of liberalism is greater. So the probability that an illiberal government follows a liberal one (weakly) decreases in the relative value of liberty. Second, more constraints on the executive (a greater $\pi$ ) increases the expected cost of security of choosing a liberal government for all levels of transparency, $q$. Therefore, more constraints on the executive induce the voter to prefer an illiberal government more. So the probability that an illiberal government follows a liberal one (weakly) increases with the amount of constraints placed on the executive by the constitution. Finally, the transparency of the liberal constitution also plays a role in the voter's choice. Proposition 6 says that whether greater transparency increases or decreases the probability of an illiberal government depends on the other parameters of the constitution as well as on the amount of transparency itself.

Proposition 6 (The rise of an illiberal democracy.) Suppose that in period $t-1$ the government is liberal. The probability that the period-t government is illiberal is weakly increasing in the executive constraints, $\pi$; weakly decreasing in the relative value of liberty, $\bar{L}$; and not necessarily monotonic in the transparency of liberal institutions, q:

1. if $\pi<1 / 2$ and $\pi<\bar{L}$, then it is single-peaked in q: it equals 0 for $q$ sufficiently small and strictly decreases with $q$ otherwise;

2. if $\pi<1 / 2$ and $\pi>\bar{L}$, then it is decreasing in $q$ : it equals 1 for $q$ sufficiently small and strictly decreases with $q$ otherwise;

3. if $\pi>1 / 2$ and $\pi<\bar{L}$, then it is increasing in $q$ : it equals 0 for $q$ sufficiently small and strictly increases with $q$ otherwise;

4. if $\pi>1 / 2$ and $\pi>\bar{L}$, then it is U-shaped in $q$ : it equals 1 for $q$ sufficiently small and strictly increases with $q$ otherwise.

Panels (a) and (b) in Figure 2 illustrate the relationship between the illiberal government's election probability and the transparency of liberal institutions, $q$, under two parametric assumptions about $\pi$. This figure captures all the cases discussed in Proposition 6.

Intuitively, Point 1 of Proposition 6 refers to a constitution in which there are few constraints on the executive and the voter values liberty very much. Then, absent any information about the period-specific threat, the voter would always elect a liberal government. The voter would resort to electing an illiberal government only if she were to observe sufficiently precise information about the current period's threat. Therefore, if the signal $s$ is sufficiently precise (large $q$ ), she elects an illiberal government whenever she observes $m_{t}=1$. Because $\pi<1 / 2$, a more precise signal sends message $m_{t}=1$ 


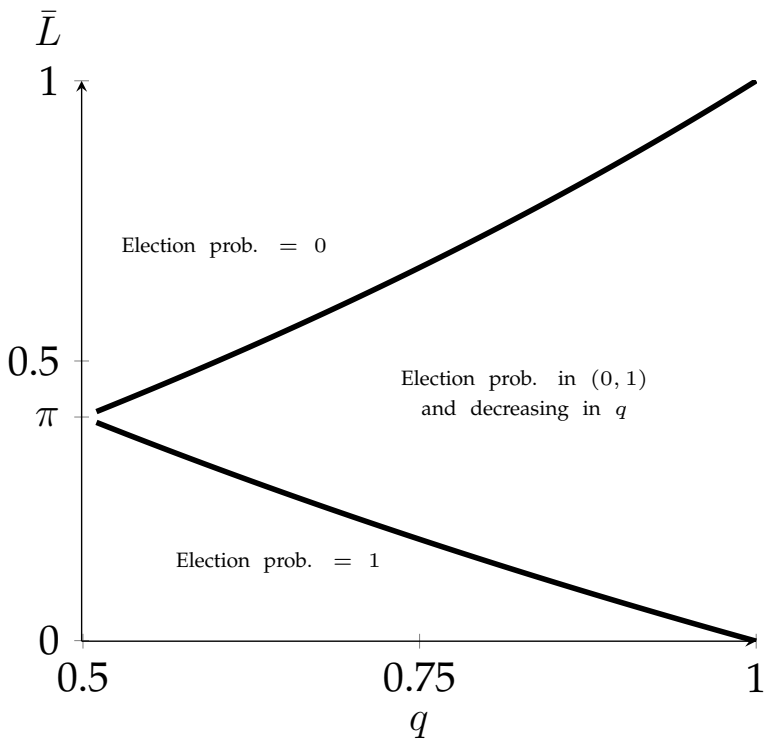

(a) $\pi=0.4$.

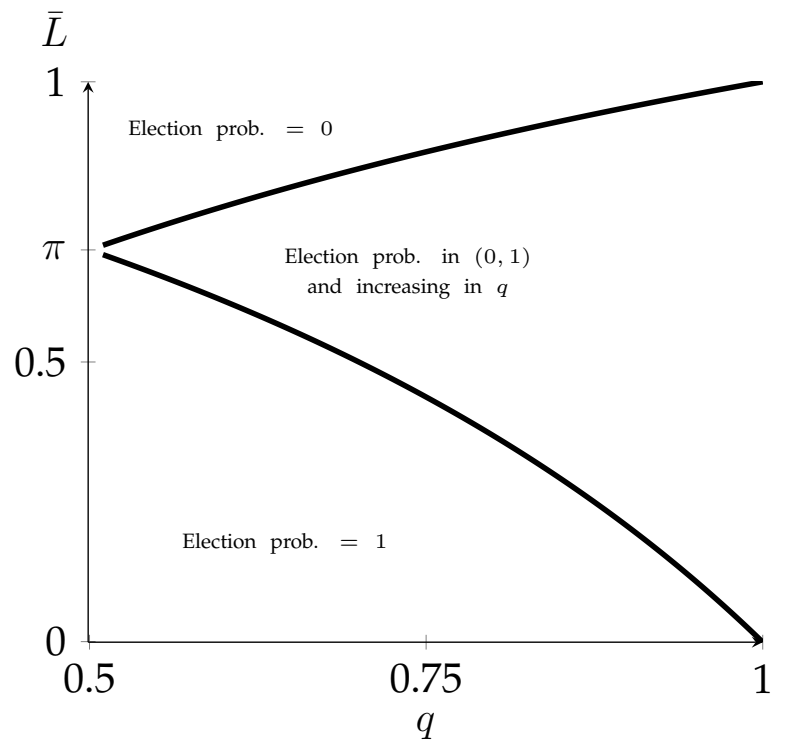

(b) $\pi=0.7$.

Figure 2: Illiberal government's election probability.

with lower probability, and therefore the probability of electing an illiberal government is strictly decreasing in $q$.

Point 2 (Point 3) refers to a situation in which there are few (many) constraints on the executive and the voter's value of liberty is smaller (greater) than the expected cost of security under full censorship, $\pi S$. In this case, the voter always prefers to elect an illiberal (liberal) government when her information is sufficiently imprecise. However, the voter would rather elect the illiberal government when the current period's threat requires illiberal means of protection $\left(\theta_{t}=1\right)$ and otherwise to elect the liberal government. Therefore, if the signal $s$ is sufficiently precise, the voter elects an illiberal government whenever she observes $m_{t}=1$. Because $\pi<1 / 2(\pi>1 / 2)$, a more precise signal sends message $m_{t}=1$ with lower (higher) probability, and therefore the probability of electing an illiberal government is strictly decreasing (increasing) in $q$.

Point 4 is a mirror image of Point 1 : the voter would elect a liberal government only if she were to observe a sufficiently precise information about the current period's threat not necessitating illiberal means of protection. For more informative signals, because $\pi>1 / 2$, the probability of electing an illiberal government is strictly increasing in $q$. 


\subsection{The reign: Optimal censorship}

We now turn to studying how different elements of the constitution $C=(\pi, q, L)$ affect an illiberal government's censorship policy. Recall from Lemmas 2 and 3 that, in stable illiberal democracies, the illiberal government is indifferent among many censorship policies, including the full censorship policy, $c_{F}$. In this section, we focus on the equilibrium where the illiberal government chooses the full censorship policy whenever it is optimal. Without loss of generality, we identify the full censorship policy, $c_{F}$, with the censorship policy that always sends $m_{t}=1$.

Proposition 7 says that greater constraints on the executive (greater $\pi$ ) increases the expected cost of security for all censorship policies, and therefore allows an illiberal government to engage in more censorship (greater $c^{*}(0)$ ). In contrast, a greater relative value of liberty (greater $\bar{L}$ ) forces an illiberal government to engage in less censorship. However, the effect of the transparency of liberal institutions, $q$, on the optimal amount of censorship depends on the other parameters of the constitution.

Proposition 7 (The reign of an illiberal democracy.) Whenever, in equilibrium, an illiberal government is elected with positive probability, the amount of censorship, $c^{*}(0)$, is weakly increasing in the constraints on the executive, $\pi$; weakly decreasing in the relative value of liberty, $\bar{L}$; and

1. if $\pi<\bar{L}$, it is increasing in the transparency of liberal institutions, $q$;

2. if $\pi>\bar{L}$, it is decreasing in the transparency of liberal institutions, $q$.

As the transparency of liberal institutions increases (greater $q$ ) there are two effects: a persuasion effect and an accountability effect. Intuitively, more transparent institutions increases an illiberal government's ability to persuade the voter to reelect the government. More precisely, when an illiberal government engages in the optimal partial censorship, upon observing message $m_{t}=1$, the voter is indifferent between electing a liberal or an illiberal government for the next period. For a given censorship policy, a more transparent liberal institution (greater $q$ ) provides the voter with greater incentive to elect an illiberal government upon observing message $m_{t}=1$. Therefore, this persuasion effect induces an illiberal government to increase the amount of censorship when the liberal institutions are more transparent. This effect is common in the Bayesian persuasion literature (Kamenica and Gentzkow, 2011; Kolotilin et al., 2019).

In our model, more transparent institutions also affects an illiberal government's censorship through an accountability effect. Recall from Lemma 1 that the voter's choice to 
reelect the illiberal government depends whether the expected cost of security exceeds the sum of the value of liberty and the accountability cost of illiberalism. Naturally, when liberal institutions are more transparent, the accountability cost of illiberalism is greater because returning to a liberal government allows the voter to make even more informed decisions in the future. To keep the voter indifferent, an illiberal government must provide the voter with greater information to compensate them for the greater accountability cost. Therefore, this accountability effect induces an illiberal government to decrease the amount of censorship when the liberal institutions are more transparent.

Proposition 7 says that the persuasion effect dominates when the constitution has few constraints on the executive and the voter values liberty so much that, absent any information about the period-specific threat, the voter would always elect a liberal government. Otherwise, the accountability effect dominates.

\subsection{The fall}

We now turn to studying what causes illiberal governments to fall if they do at all. Because of censorship, the voter is unable to cause the fall of an illiberal government as soon as the crisis is ended, i.e., as soon as $s\left(\theta_{t}\right)=0$. Instead, the only thing that may triggers a fall of an illiberal democracy is the illiberal government's failure to conceal that there is no crisis anymore: $m_{t}=0$. Therefore, in cycling democracies and in inefficient stable illiberal democracies, illiberal governments remain in power for longer than the voter would optimally choose in the absence of censorship.

We now show what factors increase the probability that an illiberal government stays in power. Proposition 8 says that an illiberal government's reelection probability is increasing in the constraints on the executive, $\pi$; decreasing in the relative value of liberty, $\bar{L}$; but not necessarily monotonic in the transparency of liberal institutions, $q$.

Proposition 8 (The fall of an illiberal democracy.) Whenever, in equilibrium, an illiberal government is elected with positive probability, it is reelected with probability weakly increasing in the constraints on the executive, $\pi$; weakly decreasing in the relative value of liberty, $\bar{L}$; and not necessarily monotonic in the transparency of liberal institutions, q. However:

(i) if $1 / 2<\pi<\bar{L}$, it is increasing in $q$;

(ii) if $\bar{L}<\pi<1 / 2$, it is decreasing in $q$.

To understand how the transparency of liberal institutions affects the ability of an illiberal government to be reelected, it is useful to write the explicit formula for the derivative of the illiberal government's reelection probability with respect to $q$. Recall that, 
in equilibrium, the voter reelects an illiberal government whenever she observes $m_{t}=1$; therefore, this formula is

$$
\begin{aligned}
& \frac{\partial \operatorname{Pr}\left[m_{t}=1 \mid c^{*}\right]}{\partial q} \\
& =\underbrace{\left(\frac{\partial \operatorname{Pr}\left[s\left(\theta_{t}\right)=1\right]}{\partial q}+c^{*}(0) \frac{\partial \operatorname{Pr}\left[s\left(\theta_{t}\right)=0\right]}{\partial q}\right)}_{\text {Mechanical }}+\underbrace{\operatorname{Pr}\left[s\left(\theta_{t}\right)=0\right] \frac{\partial c^{*}(0)}{\partial q}}_{\text {Strategic }} .
\end{aligned}
$$

This formula highlights that there are two effects of transparency on the illiberal government's reelection. First, there is a mechanical component whereby, for a given censorship policy, the transparency of the liberal institutions affects the probability that the voter observes message $m_{t}=1$ because the institutions determine the likelihood of an underlying signal $s\left(\theta_{t}\right)=1$. The direction of the mechanical effect depends on the constraints on the executive, $\pi$. When $\pi<1 / 2(\pi>1 / 2)$, a more transparent institution produces an underlying signal $s\left(\theta_{t}\right)=1$ with lower (higher) probability and, all else equal, the illiberal government's reelection probability decreases (increases) with $q$. Second, there is a strategic component whereby the transparency of the liberal institutions affects the optimal censorship policy of an illiberal government. By Proposition 7, when $\pi<\bar{L}(\pi>\bar{L})$ the persuasion (accountability) effect determines the sign of the strategic component, and the illiberal government's reelection probability increases (decreases) with $q$.

Point 1 (Point 2) of Proposition 8 refers to a constitution where the persuasion (accountability) effect determines the sign of the strategic component and the mechanical component operates in the same direction; therefore, the illiberal government's reelection probability monotonically increases (decreases) with $q$. In the remaining cases, the two components have opposite signs. As illustrated by Figure 3, for low values of $q$, the strategic component dominates but, for high values, the marginal effect of $q$ on the optimal censorship policy vanishes and, therefore, the mechanical component dominates.

\section{Constitutional design and welfare}

We now turn to the problem of the optimal design of a constitution. One immediate implication of our analysis is that excessive constraints on the executive (high $\pi$ ) necessarily lead to illiberalism. Intuitively, excessive constraints render liberal governments ineffective and induce voters to elect illiberal governments that promise economic performance, efficient public services, and protection from domestic and international violence. This result resonates with the literature that roots the rise of illiberal governments in the inef- 


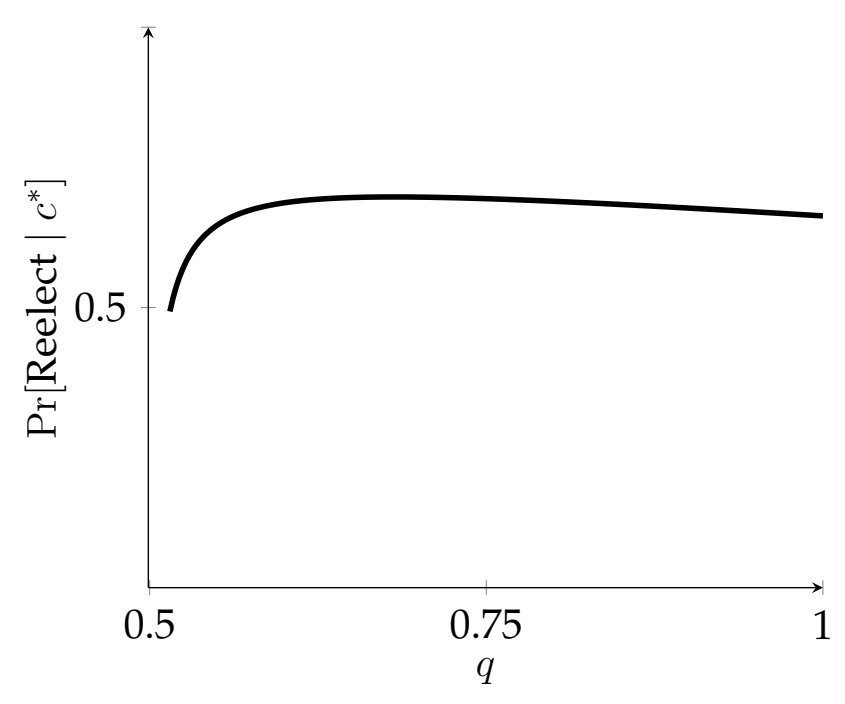

(a) $\bar{L}=1 / 3, \pi=0.32, \delta=0.9$.

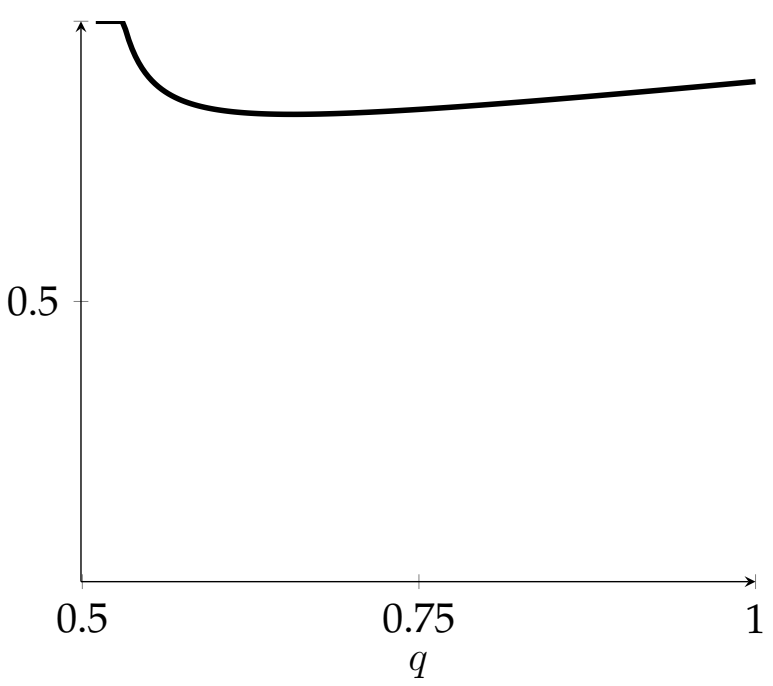

(b) $\bar{L}=3 / 4, \pi=0.76, \delta=0.9$.

Figure 3: The illiberal government's reelection probability.

fectiveness of liberal democratic institutions (Berman, 2019; Matthijs and Blyth, 2018; see also Rodrik, 2000). Howell and Moe (2020) suggest that constitutional reforms that give greater power to the U.S. executive (and the president, in particular) are needed to safeguard the future of American liberal democracy. However, reducing constraints on the executive is not without costs: more constraints on the executive are needed to guarantee greater individual freedoms. This is captured by our function $L=\mathcal{L}(\pi)$ in Section 2.2. Therefore, our framework allows us to derive implications for the design of the optimal stable liberal constitution: a constitution that maximizes liberty, $\mathcal{L}(\pi)$, and induces a stable liberal democracy, i.e., subject to

$$
\mathcal{L}(\pi)>\mu_{t}^{*}\left(1, c_{\ell}\right) S .
$$

The right hand side of (8) is increasing in $\pi$. Therefore, the optimal stable liberal constitution features constraints on the executive $\pi^{*}<1$ unless $\mathcal{L}(1)>S$, i.e., unless a government that cannot protect against any threat delivers liberty that the voter values more than security.

The right hand side of (8) is also increasing in the transparency of liberal institutions, $q$. Therefore, the optimal constraints on the executive, $\pi^{*}$, will crucially depend on $q$. For example, if $\mathcal{L}(\pi)=\alpha+\beta \pi$, for $\alpha, \beta>0$, then the optimal constraints on the executive, 
$\pi^{*}(q)$, are decreasing in $q \cdot{ }^{31}$ An interpretation of this result is that technological changes that affect the quality of information observed by voters affect the optimal constraints on the executive. In particular, the arrival of technologies that increase transparency must be accompanied by reductions in the constraints on the executive to safeguard against illiberalism.

Transparency is also determined by the design of the institutions. In particular, more constraints on the executive guarantee greater independence of the bureaucracy and the media. This is captured by our function $q=\mathcal{Q}(\pi)$ in Section 2.2. Therefore, the design of the optimal stable liberal constitution involves solving the following problem:

$$
\begin{array}{ll}
\sup _{C=(\pi, q, L)} L \\
\text { s.t. } \quad L>\mu_{t}^{*}\left(1, c_{\ell}\right) S, \\
& L=\mathcal{L}(\pi), \\
& q=\mathcal{Q}(\pi) .
\end{array}
$$

The solution yields executive constraints, $\pi^{*}$, such that

$$
\mathcal{L}\left(\pi^{*}\right)=\frac{\pi^{*} \mathcal{Q}\left(\pi^{*}\right)}{\pi^{*} \mathcal{Q}\left(\pi^{*}\right)+\left(1-\pi^{*}\right)\left(1-\mathcal{Q}\left(\pi^{*}\right)\right)} S .
$$

The possibly detrimental effects of greater transparency are most evident when considering the welfare implications of different constitutions. To make ideas precise, suppose there is a continuum of voters, $j$, indexed by their relative value of liberty, $\bar{L}_{j}$, and decisions are made via majority rule. Then the pivotal voter is the voter with median relative value of liberty. Therefore, the single voter in our model corresponds to this median voter. Any increase in transparency, including a marginal increase that moves the constitution from a stable liberal democracy to a cycling liberal-illiberal democracy, benefits the median voter. However, it can be shown that this same marginal increase in transparency harms every voter with a higher relative value of liberty and, therefore, may reduce aggregate welfare.

\footnotetext{
${ }^{31}$ If $\alpha+\beta>1$, then the unconstrained and constrained solutions coincide, and so $\pi^{*}(q)=1$ for all $q$. Otherwise, there is a unique solution $\pi^{*}(q): \alpha+\beta \pi^{*}=\frac{\pi^{*} q}{\pi^{*} q+\left(1-\pi^{*}\right)(1-q)} S$, which is strictly decreasing in $q$.
} 


\section{Paths to autocracy and democratic stability}

A major concern expressed by political leaders, scholars, and commentators is that illiberal democracies may constitute a first step toward autocracy (see, e.g., Lührmann and Lindberg, 2019; Rhodes, 2020). In reality, once an illiberal government rises to power, its ability to operate beyond constitutional constraints may not be restricted to information manipulation. We see two possible paths through which illiberal governments may build an autocracy. A first path is through the manipulation of the liberty-security tradeoff. A second path is through the direct repression of electoral accountability.

Manipulating security. We extend our model to allow the illiberal government to manipulate the voter's value of security. In particular, in each period that the illiberal government is in power, with probability $\zeta$, it can choose to increase the value of security, $S$, to $S^{\prime}$ such that

$$
L \leq \mu_{t}^{*}\left(0, c_{\ell}\right) S^{\prime}
$$

For example, the illiberal government can engage in aggressive diplomacy with a foreign power or exacerbate internal conflicts with separatists. From the point of view of the voter, this increases the expected security cost of electing a liberal government which cannot employ illiberal measures to protect the voter from foreign invasions or domestic terrorism. Condition 13 says that the increased value of security is large enough to induce the voter to forever prefer an illiberal government, thus inducing a de facto autocracy (see Proposition 2).

Repressing accountability. We extend our model to allow the illiberal government to directly repress electoral accountability, thus seizing power and establish an autocracy. Formally, in each period that the illiberal government is in power, with probability $\gamma$, it can choose to overthrow the constitution and seize power. If the government chooses to overthrow the constitution, from that period onward, there is no further election and the illiberal government is in power forever.

In equilibrium, illiberal governments obviously always choose to seize a chance to manipulate security or repress accountability. Therefore, both extensions imply that whenever the voter elects an illiberal government, there is a positive probability that this will induce an autocracy. In the long run, this means that a constitution either induces a stable 
liberal democracy, or it will result in an autocracy. ${ }^{32}$ The greater the probability that an illiberal government can build an autocracy (greater $\zeta$ or $\gamma$ ), the sooner any non-stable liberal democracy becomes an autocracy. However, Proposition 9 says that a greater probability that an illiberal government can build an autocracy allows for a greater set of constitutions to induce a stable liberal democracy.

Proposition 9 (Long-run democratic stability.) For $\zeta>0$ or $\gamma>0$, as $t$ grows, all constitutions induce either a stable liberal democracy or an autocracy. A constitution induces a stable liberal democracy in the long-run if the relative value of liberty $\bar{L}$ is greater than a threshold $\bar{\kappa}^{\prime}(\pi, q, \delta ; \zeta, \gamma)$ which decreases with $\zeta$ and $\gamma$.

Intuitively, when electing an illiberal government comes with a greater risk of a total loss of accountability, the voter is more wary of the potential consequences of such a decision. Therefore, she elects an illiberal government only if the expected cost of security is very large. Thus, the set of constitutions that allow for a stable liberal democracy to emerge is greater.

We can interpret the parameters $\zeta$ and $\gamma$ as measuring the weakness of checks and balances preventing total executive takeover. Thus, our result says that stronger checks and balances, while reducing the speed at which illiberal democracies may turn into autocracies, may actually induce democracies to turn illiberal with greater probability, and in the long run lead to autocracy.

Importantly, two types of long-run regimes may arise in equilibrium. First, some stable liberal democracies may be inefficient. For some constitutions, absent the risk that illiberal governments can build an autocracy, the voter would prefer to cycle between liberal and illiberal governments. However, because illiberal democracies may turn into autocracies, the voter refrains from electing an illiberal government and instead prefers to endure the full cost of security of liberalism. This happens when the liberal constraints on the executive are intermediate.

Second, some long-run autocracies are also inefficient for the median voter. For some constitutions, the voter prefers to cycle between liberal and illiberal governments. However, she chooses illiberalism conscious that this may lead with positive probability to a long-run autocracy, which on average offers too much security and too little liberty.

Informational legacy of illiberalism. Another realistic dynamic effect of illiberalism is that information manipulation may have long-lasting effects on the quality of some institutions of control. For example, a censored bureaucracy may find it hard to rebuild

\footnotetext{
${ }^{32}$ However, this may take time and even repeated cycles between liberal and illiberal governments.
} 
capabilities and experience after an illiberal spell. Similarly, intimidated media may not recover immediately after the fall of an illiberal government. In our model, this amounts to a permanent fall in $q$ following an illiberal government. Notice that this means that the accountability cost of illiberalism is no longer constant: it is large before the voter ever elects an illiberal government, but it is small (in some cases even equal to zero) once the illiberal government rises to power. As a consequence, the voter is more wary of electing an illiberal government, therefore reducing the probability of a rise of an illiberal democracy, but she also is less likely to return to liberalism once she has elected an illiberal government, reducing the chances of a fall of an illiberal democracy.

\section{Empirical relevance}

The focus of our theory is at the voter's level. In particular, we offer a framework to think about variation in support for liberalism even in consolidated democracies, which in turn may lead to the rise of an illiberal democracy. Our key idea is that a greater belief that individual welfare is under threat should come with lower support for liberal aspects of democracy but not necessarily with an outright rejection of democracy. We now argue that this premise is consistent with real-world data. We use data from Wave 6 of the World Value Survey (2010-2014), focusing our attention to respondents in fully consolidated democracies, i.e., countries scoring a 10 out of 10 in the Polity 5 democracy score in 2010. We study how different fear factors correlate with support for liberal elements of democratic constitutions. We use two important variables capturing fear: the fear of terrorist attacks and the fear of losing employment (or not finding employment). ${ }^{33}$ We measure (positive or negative) support for liberal aspects of democratic constitutions via questions regarding support for the protection of civil rights (positive), and for "having a strong leader who does not have to bother with parliament and elections" (negative).

Figure 4 shows that fears of terrorist attacks and losing employment strongly correlate with lower support for the protection of civil rights in democracy and greater support for a strong leader. However, the bottom panels of Figure 4 show that fears of terrorism or of losing employment do not have a similarly clear impact on support for democracy in general. All these results replicate in linear regressions with country fixed effects; all relations have the expected direction and are highly statistically significant, bar for the relation between fear of terrorism and support for democracy. The results also extend to including all democracies (Polity5 score of 6-10) but the effect of fear on civil rights

\footnotetext{
${ }^{33}$ The results are qualitatively similar if we use the fear of a "war involving my country."
} 
protections is lost, perhaps because the importance of civil rights protection is perceived as more fundamental among citizens of democracies with very marginal scores. ${ }^{34}$

Albeit far from establishing any causal relation, the data support the view that individual fears are connected with lower support of key liberal aspects of democratic constitutions. Even in Western consolidated democracies, economic insecurity maps into much stronger preferences for governments that do not need to bother with the procedural aspects of democratic decision-making. These results naturally map into the mechanics of our model: upon observing information suggesting that individual welfare is under greater threat, a voter's expected cost of security rises, so that she may more likely prefer an illiberal government: one that provides less liberties, such as the protection of civil rights, but provides security through the effective action of a strong and less constrained leadership.

Our theory offers a mechanism through which these individual tendencies towards illiberalism become consequential: if the median voter prefers an illiberal government, she will elect one, leading the country to cycles of illiberalism, a stable illiberal democracy, or even to an autocracy. Survey data may not necessarily represent consequential preferences-perhaps only reflecting the respondents' frustration with the complications of democracy. However, even within our sample of consolidated democracies, countryaverage support for a strong leadership negatively correlate with the v-Dem measure of liberal democracy in 2010 (p-value: 0.023), suggesting that survey data, at least about the support for strong leaders, capture a substantial phenomenon that affects both voters' preferences and the action of governments. Therefore, we use this variable as a measure of voters' support for illiberalism.

A distinctive feature of our model is that too many constraints on the executive aimed at guaranteeing liberty may induce worried voters to prefer an illiberal government. More specifically, our theory predicts that fears of terrorism, war, or economic insecurity should translate into preferences for illiberalism more in countries that have more stringent constraints on the executive. Following Besley and Persson (2016) and Besley and Mueller (2018), we measure executive constraints using a dummy variable which is equal to one when a country in 2010 receives the highest score (7) on this basis on the Polity 5 data. In order to observe variance in this measure, we study the sample of all democracies (a score of 6 or more in the Polity 5 democracy measure). We report in Table 1 the results of regressing our preferred measure of support for illiberalism (respondents' support for

\footnotetext{
${ }^{34}$ In addition, the connection between economic security and support for democracy in general is lost and, if anything, fear of terrorism seem to foster the support for democracy in general in marginal democracies.
} 


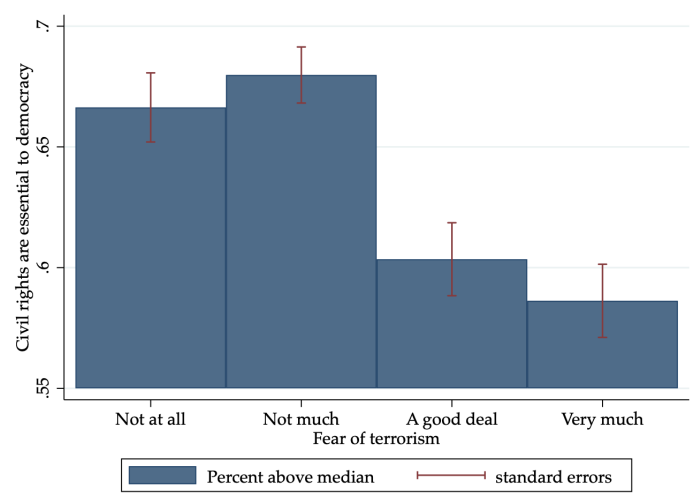

(a) Terrorism and civil rights

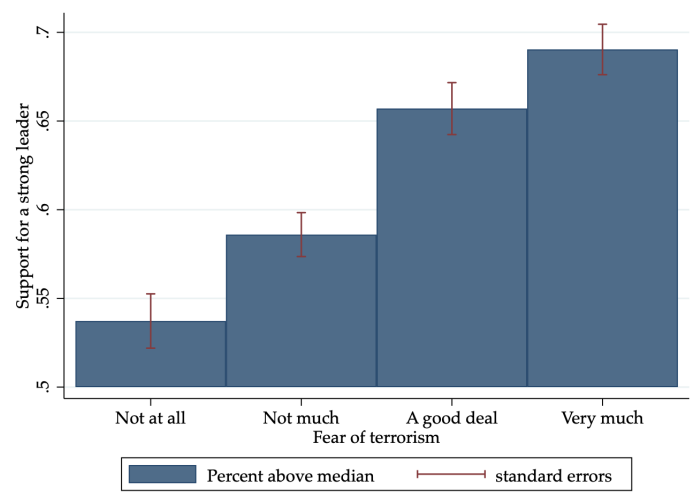

(c) Terrorism and strong leader

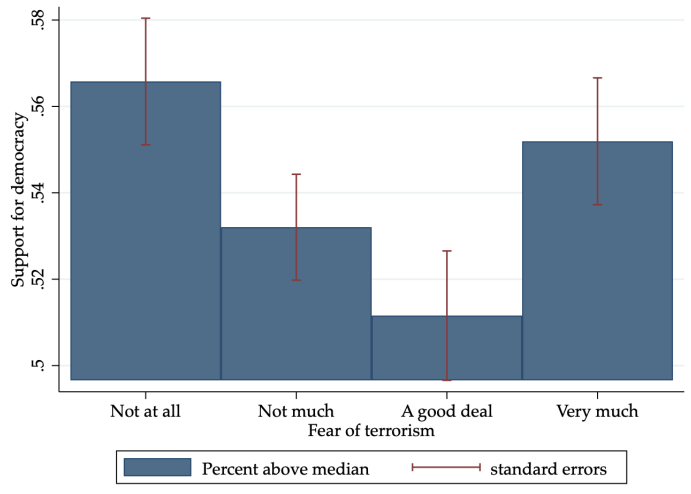

(e) Terrorism and democracy

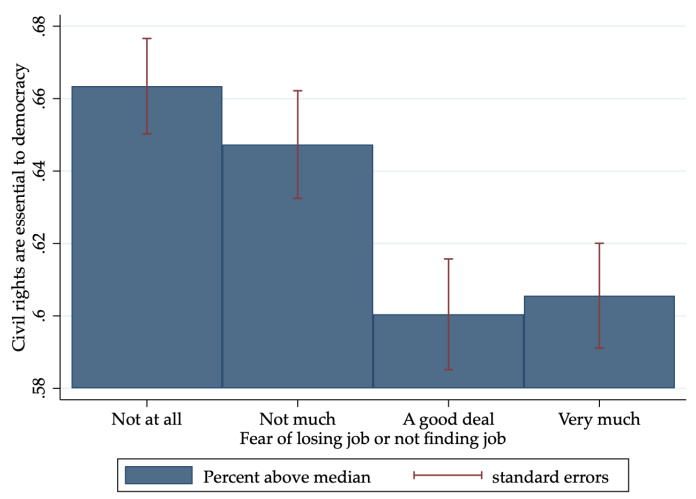

(b) Economic security and civil rights

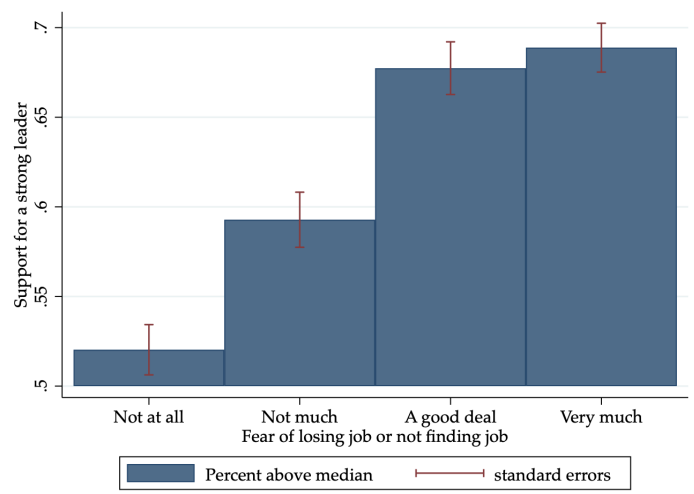

(d) Economic security and strong leader

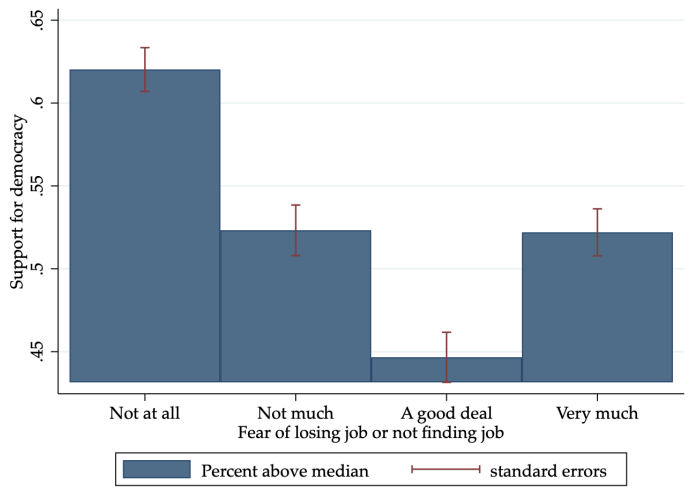

(f) Economic security and democracy Percentage of respondents whose answer is weakly greater than the median answer to that question. Panels (a) and (b): Many things are desirable, but not all of them are essential characteristics of democracy: Civil rights protect people from state oppression (scale 1-10). Panels (c) and (d): Would you say it is a very good, fairly good, fairly bad or very bad way of governing this country: Having a strong leader who does not have to bother with parliament and elections? Panels (e) and (f): How important is it for you to live in a country that is governed democratically? (scale 1-10). X-axes: To what degree are you worried about the following situations?: A terrorist attack (left panels); losing my job or not finding a job (right panels).

Figure 4: Word Value Survey (2010-2014) 


\begin{tabular}{lcc}
\hline \hline & \multicolumn{2}{c}{ Support for a strong leader } \\
& $(1)$ & $(2)$ \\
\hline Fear of terrorism & -0.0139 & \\
& $(0.0294)$ & \\
Fear of losing job & & -0.0256 \\
& $-0.630^{* * *}$ & $(0.0383)$ \\
Executive constraints & $(0.169)$ & $(0.167)$ \\
Fear of terrorism $\times$ Executive constraints & $0.154^{* * *}$ & \\
& $(0.0381)$ & $0.165^{* * *}$ \\
Fear of losing job $\times$ Executive constraints & & $(0.0459)$ \\
\hline \multirow{2}{*}{ Observations } & & \\
\hline \hline
\end{tabular}

Clustered standard errors in parentheses. ${ }^{*} p<0.10,{ }^{* *} p<0.05,{ }^{* * *} p<0.01$.

Table 1: Executive constraints and the connection between fear and illiberalism.

a strong leader) on our measures of fear, the executive constraints dummy, and the interaction term between fear and executive constraints. Consistently with our theory, the effect of fear on preferences for illiberalism are larger-and in fact exist only-in countries that have stronger constraints on the executive.

Our model also offers new perspectives into aggregate data on censorship and the longevity of illiberal governments. In our model, as long as an illiberal government is in power, its reelection probability is constant. Therefore, for a given constitution, the longevity of an illiberal government follows a geometric distribution and the comparative statics of the illiberal government's reelection probability extends to its expected longevity. However, from an empirical perspective, if the details of the constitution, $C=(\pi, L, q)$, are not fully observed and the observations come from a distribution of constitutions, the average longevity of illiberal governments across constitutions does not follow a geometric distribution. Instead, the expected residual life of the average illiberal government is increasing with the maturity of the illiberal democracy. Therefore, although illiberal democracies may be duration dependent in aggregate (as observed by Buchheim and Ulbricht, 2020), our model suggests that this result would disappear if one could appropriately control for the details of the underlying constitution.

In some cases, it may be possible to observe the censorship policy of an illiberal government and its longevity. Our model predicts that, in equilibrium, an illiberal government's longevity correlates (but is not caused by) the amount of censorship-an empirical 
regularity observed by Hollyer et al. $(2011,2015)$.

\section{Conclusion}

We proposed a theory of the rise and fall of illiberal democracies. We showed that, during times of crisis, voters may choose to elect illiberal governments that, by operating beyond the constraints of a liberal constitution, offer greater security and less liberty but may also manipulate information. We showed that the manipulation (or censoring) of information reduces effective electoral accountability. Therefore, the tradeoff that we highlight for the voters is one between liberty, security, and accountability.

By focusing on the ability of illiberal government to manipulate information, we drew insights into what makes a liberal constitution stable. First, the constitution must give sufficient powers to the government to address emergencies. In this sense, an ideal liberal constitution that perfectly protects individual liberties and rights is ineffective: it inevitably leads to illiberal governments that systematically infringe those same rights. Importantly, the effect of too many and too stringent constraints on the executive may be exacerbated by excessive transparency. In other words, in a world in which information leaks are unavoidable, a stable liberal democracy requires greater powers in the hands of the executive.

We also derived the conditions under which voters may resort to illiberal governments even when they expect such governments to be able to completely overthrow the checks and balances of democracy and dispense with elections altogether. The key insight from this analysis is that cycles of illiberalism are short-term symptoms of a longrun tendency to authoritarianism. Our results suggest that stronger checks and balances, while delaying the process of executive takeover, may nonetheless be counterproductive as they induce voters to be excessively optimistic about experimenting with short-term illiberal spells. If illiberal democracies are a step towards autocracy, then the only safety mechanism against them is to avoid them altogether by increasing the effectiveness of the government and possibly balancing executive constraints with transparency.

Our model focuses on the popular demand for illiberalism in that it assumes that viable illiberal candidates always exist. In reality, whether such candidates exist may also depend on supply-driven factors such as the political and party system. For example, Berman and Snegovaya (2019) and Rosenbluth and Shapiro (2018) argue the increase in demand for illiberal candidates is explained by recent trends in the design and ideology of political parties and that parties have a role in stemming the supply of illiberal candidates (see also Benedetto, Hix and Mastrorocco, 2020). Grillo and Prato (2020) show 
that even leaders who have no preferences for illiberal policies may partially adopt them to gain electoral advantages when voters have reference-dependent preferences. These supply-driven factors are likely to exacerbate the vulnerability of liberal constitutions to the changes in voters' demand for illiberalism.

Our results about the role played by transparency in liberal democracies may offer insights into how to interpret the relation between the expansion of internet, $3 \mathrm{G}$ networks, and social media and the rise of populism in Europe (Campante, Durante and Sobbrio, 2018; Guriev, Melnikov and Zhuravskaya, 2020). In our framework voters always hold consistent beliefs about the probability that their welfare is under threat. In reality voters' beliefs may overreact to information, overestimate small probabilities (for example, the probability of dying in a terrorist attack), and in general be on average inconsistent with reality (Alesina, Miano and Stantcheva, 2020; Alesina, Stantcheva and Teso, 2018). Therefore, our results are likely to underestimate the probability that the median voter may resort to inefficient illiberal regimes, increasing the potential cost of constitutions that are more exposed to the menace of illiberalism. 


\section{References}

Acemoglu, Daron, Giuseppe De Feo, Giacomo De Luca, and Gianluca Russo, “War, Socialism and the Rise of Fascism: An Empirical Exploration," NBER Working Paper No. $27854,2020$.

Aghion, Philippe, Alberto Alesina, and Francesco Trebbi, "Endogenous political institutions," The Quarterly Journal of Economics, 2004, 119 (2), 565-611.

Alesina, Alberto, Armando Miano, and Stefanie Stantcheva, "The Polarization of Reality," AEA Papers and Proceedings, 2020, 110, 324-28.

Alesina, Alberto, Stefanie Stantcheva, and Edoardo Teso, "Intergenerational Mobility and Preferences for Redistribution," American Economic Review, 2018, 108 (2), 521-54.

Anelli, Massimo, Italo Colantone, and Piero Stanig, "We Were the Robots: Automation and Voting Behavior in Western Europe," IZA Discussion Paper No. 12485, 2019.

Autor, David, David Dorn, Gordon Hanson, and Kaveh Majlesi, "Importing Political Polarization? The Electoral Consequences of Rising Trade Exposure," American Economic Review, 2020, 110 (10), 3139-3183.

Benedetto, Giacomo, Simon Hix, and Nicola Mastrorocco, "The Rise and Fall of Social Democracy, 1918-2017," American Political Science Review, 2020.

Berman, Sheri, "Populism is a Symptom Rather than a Cause: Democratic Disconnect, the Decline of the Center-Left, and the Rise of Populism in Western Europe," Polity, 2019, 51 (4), 654-667.

Berman, Sheri and Maria Snegovaya, "Populism and the Decline of Social Democracy," Journal of Democracy, 2019, 30 (3), 5-19.

Bernhardt, Dan, Stefan Krasa, and Mehdi Shadmehr, "Demagogues and the Fragility of Democracy," UIUC Working Paper, 2019.

Besley, Timothy and Hannes Mueller, "Cohesive institutions and the distribution of political rents: Theory and evidence," in "Institutions, Governance and the Control of Corruption," Springer, 2018, pp. 165-208.

Besley, Timothy and Torsten Persson, "Democratic Values and Institutions," London School of Economics and Political Science Working Paper, 2016. 
Besley, Timothy and Torsten Persson, "Democratic Values and Institutions," American Economic Review: Insights, 2019, 1 (1), 59-76.

Buchheim, Lukas and Robert Ulbricht, "A quantitative Theory of Political Transitions," Review of Economic Studies, 2020, 87 (4), 1726-1756.

Campante, Filipe, Ruben Durante, and Francesco Sobbrio, "Politics 2.0: The multifaceted effect of broadband internet on political participation," Journal of the European Economic Association, 2018, 16 (4), 1094-1136.

Cheibub, José Antonio, Ji Yeon Jean Hong, and Adam Przeworski, "Rights and Deaths: Government Reactions to the Pandemic," SSRN Working Paper 3645410, 2020.

Colantone, Italo and Piero Stanig, "The Trade Origins of Economic Nationalism: Import Competition and Voting Behavior in Western Europe," American Journal of Political Science, 2018, 62 (4), 936-953.

Colantone, Italo and Piero Stanig, "The Surge of Economic Nationalism in Western Europe," Journal of Economic Perspectives, 2019, 33 (4), 128-51.

Collier, Paul, “The Political Economy of Natural Resources," Social Research, 2010, 77 (4), $1105-1132$.

Coppedge, Michael, John Gerring, Carl Henrik Knutsen, Staffan I. Lindberg, Jan Teorell, David Altman, Michael Bernhard, M. Steven Fish, Adam Glynn, Allen Hicken, Anna Luhrmann, Kyle L. Marquardt, Kelly McMann, Pamela Paxton, Daniel Pemstein, Brigitte Seim, Rachel Sigman, Svend-Erik Skaaning, Jeffrey Staton, Steven Wilson, Agnes Cornell, Nazifa Alizada, Lisa Gastaldi, Haakon Gjerløw, Garry Hindle, Nina Ilchenko, Laura Maxwell, Valeriya Mechkova, Juraj Medzihorsky, Johannes von Römer, Aksel Sundström, Eitan Tzelgov, Yi-ting Wang, Tore Wig, and Daniel Ziblatt, V-Dem [Country-Year/Country-Date] Dataset v10. Varieties of Democracy (V-Dem) Project. https://doi.org/10.23696/vdemds20.2020.

Department of Homeland Security Office of Inspector General, "Whistleblower Reprisal Complaint. Murphy, Brian, Principal Deputy Under Secretary, Department of Homeland Security Office of Intelligence \& Analysis," September 2020.

Edmond, Chris, "Information Manipulation, Coordination, and Regime Change," Review of Economic Studies, 2013, 80 (4), 1422-1458. 
Fearon, James D., "Self-enforcing Democracy," The Quarterly Journal of Economics, 2011, $126(4), 1661-1708$.

Felshtinsky, Yuri and Vladimir Pribylovskyr, The Age of Assassins: The Rise and Rise of Vladimir Putin, Gibson Square Books, 2008.

Foa, Roberto Stefan and Yascha Mounk, "The Danger of Deconsolidation: The Democratic Disconnect," Journal of Democracy, 2016, 27 (3), 5-17.

Foa, Roberto Stefan and Yascha Mounk, "The Signs of Deconsolidation," Journal of Democracy, 2017, 28 (1), 5-15.

Fudenberg, Drew and Jean Tirole, "Perfect Bayesian Equilibrium and Sequential Equilibrium," Journal of Economic Theory, 1991, 53 (2), 236-260.

Graham, Matthew H. and Milan W. Svolik, "Democracy in America? Partisanship, Polarization, and the Robustness of Support for Democracy in the United States," American Political Science Review, 2020, 114 (2), 392-409.

Gratton, Gabriele and Massimo Morelli, "Optimal Checks and Balances Under Policy Uncertainty," CEPR Duscussion Paper No. DP14745, 2020.

Grillo, Edoardo and Carlo Prato, "Reference Points and Democratic Backsliding," SSRN Working Paper 3475705, 2020.

Guiso, Luigi, Helios Herrera, Massimo Morelli, and Tommaso Sonno, "Global Crises and Populism: The Role of Eurozone Institutions," Economic Policy, 2019, 34 (97), 95139.

Guiso, Luigi, Helios Herrera, Massimo Morelli, and Tommaso Sonno, "Economic Insecurity and the Demand of Populism in Europe," Einaudi Institute for Economics and Finance Working Paper, 2020.

Guriev, Sergei and Daniel Treisman, "Informational Autocrats," Journal of Economic Perspectives, 2019, 33 (4), 100-127.

Guriev, Sergei and Daniel Treisman, "The Popularity of Authoritarian Leaders: A Crossnational Investigation," Forthcoming in World Politics, 2020.

Guriev, Sergei and Daniel Treisman, "A Theory of Informational Autocracy," Journal of Public Economics, 2020, 186, 104158. 
Guriev, Sergei and Elias Papaioannou, "The Political Economy of Populism," CEPR Discussion Paper No. DP14433, 2020.

Guriev, Sergei, Nikita Melnikov, and Ekaterina Zhuravskaya, "3G Internet and Confidence in Government," CEPR Discussion paper DP14022-8, 2020.

Hollyer, James R., B. Peter Rosendorff, and James Raymond Vreeland, “Democracy and Transparency," The Journal of Politics, 2011, 73 (4), 1191-1205.

Hollyer, James R., B. Peter Rosendorff, and James Raymond Vreeland, "Measuring Transparency," Political Analysis, 2014, 22 (4), 413-434.

Hollyer, James R., B. Peter Rosendorff, and James Raymond Vreeland, "Transparency, Protest, and Autocratic Instability," American Political Science Review, 2015, 109 (4), 764784.

Howell, William G. and Terry M. Moe, Presidents, Populism, and the Crisis of Democracy, University of Chicago Press, 2020.

Howell, William G., Kenneth Shepsle, and Stephane Wolton, "Executive Absolutism: A Model," SSRN Working Paper 3440604, 2019.

Huq, Aziz and Tom Ginsburg, "How to Lose a Constitutional Democracy," UCLA Law Review, 2018, 65, 78 .

Inglehart, R., C. Haerpfer, A. Moreno, C. Welzel, K. Kizilova, J. Diez-Medrano, M. Lagos, P. Norris, E. Ponarin, B. Puranen et al., ed., World Values Survey: Round Six - Country-Pooled Datafile 2010-2014. Version: http://www. worldvaluessurvey . org/WVSDocumentationWV6. jsp., Madrid: JD Systems Institute, 2014.

Jones, Benjamin F. and Benjamin A. Olken, "Do Leaders Matter? National Leadership and Growth Since World War II," The Quarterly Journal of Economics, 2005, 120 (3), 835864.

Kamenica, Emir and Matthew Gentzkow, "Bayesian Persuasion," American Economic Review, 2011, 101 (6), 2590-2615.

Kolotilin, Anton, Tymofiy Mylovanov, and Andriy Zapechelnyuk, "Censorship as Optimal Persuasion," SSRN Working Paper 3501474, 2019.

Krieckhaus, Jonathan, "Democracy and Economic Growth: How Regional Context Influences Regime Effects," British Journal of Political Science, 2006, pp. 317-340. 
Lührmann, Anna and Staffan I. Lindberg, "A Third Wave of Autocratization is Here: What is New About It?," Democratization, 2019, 26 (7), 1095-1113.

Luo, Zhaotian and Adam Przeworski, "Democracy and Its Vulnerabilities: Dynamics of Democratic Backsliding," SSRN Working Paper 3469373, 2019.

Luo, Zhaotian and Arturas Rozenas, "Ruling the Ruling Coalition: Information Control and Authoritarian Power-Sharing," SSRN Working Paper 2978254, 2019.

Marshall, Monty G. and Ted Robert Gurr, Polity5: Political Regime Characteristics and Transitions, 1800-2018, Polity5 Project, Center for Systemic Peace, 2020.

Matthijs, Matthias and Mark Blyth, "When is it rational to learn the wrong lessons? Technocratic authority, social learning, and euro fragility," Perspectives on Politics, 2018, $16(1), 110-126$.

Montesquieu, Charles de Secondat Baron de, The Spirit of Laws, T. Nugent. New York: Hafner, 1949 [1750].

Mounk, Yascha, The People vs. Democracy: Why Our Freedom Is in Danger and How to Save It, Harvard University Press, 2018.

Mudde, Cas and Cristóbal Rovira Kaltwasser, Populism: A Very Short Introduction, Oxford University Press, 2017.

Mukand, Sharun W and Dani Rodrik, "The political economy of liberal democracy," The Economic Journal, 2020, 130 (627), 765-792.

Nalepa, Monika, Georg Vanberg, and Caterina Chiopris, "Authoritarian Backsliding," University of Chicago Working Paper, 2020.

Orbán, Viktor, "Prime Minister Viktor Orbán's Speech at the 25th Bálványos Summer Free University and Student Camp," Prime Minister of Hungary Office, https://www.kormany.hu/en/the-prime-minister/the-primeminister-s-speeches/prime-minister-viktor-orban-s-speech-atthe-25th-balvanyos-summer-free-university-and-student-camp, Retrieved 13 September 2020. July 2014.

Posner, Eric A. and Adrian Vermeule, The Executive Unbound: After the Madisonian Republic, Oxford Scholarship Online, 2011.

Rhodes, Ben, "The Path to Autocracy," The Atlantic, 2020, (June 15). 
Rodrik, Dani, "How Far Will International Economic Integration Go?," Journal of Economic Perspectives, 2000, 14 (1), 177-186.

Rosenbluth, Frances and Ian Shapiro, Responsible Parties: Saving Democracy from Itself, Yale University Press, 2018.

Sachs, Jeffrey D., "Social Conflict and Populist Policies in Latin America," Technical Report, National Bureau of Economic Research 1989.

Satter, David, Darkness at Dawn: The Rise of the Criminal Russian State, New Haven: Yale Univ. Press, 2003.

Sgueo, Gianluca, "The Influence of Transparency on Addressing Populism in the EU," SSRN Working Paper 3137099, 2018.

Svolik, Milan W., "Polarization versus Democracy," Journal of Democracy, 2019, 30 (3), 20-32.

Svolik, Milan W., "When Polarization Trumps Civic Virtue: Partisan Conflict and the Subversion of Democracy by Incumbents," Quarterly Journal of Political Science, 2020, 15 (1), 3-31.

Szeidl, Adam and Ferenc Szucs, "Media Capture Through Favor Exchange," Forthcoming in Econometrica, 2020.

Wittes, Benjamin, "Against a Crude Balance: Platform Security and the Hostile Symbiosis Between Liberty and Security," The Brookings Institution and Harvard Law School: Project on Law and Security, 2011. 


\section{A Omitted proofs}

Proof of Lemma 1. By Definition 1, in any equilibrium, for any period $t$, message $m_{t}$, censorship policy $c_{t}$, and continuation strategies $\sigma^{*}$, the voter elects an illiberal government if and only if

$$
\begin{aligned}
& \mu_{t}\left(m_{t}, c_{t}\right) S \\
& \geq L+\delta\left[\mathbb{E}\left[\sum_{\tilde{t}=t+1}^{\infty} \delta^{(\tilde{t}-t-1)} v\left(g_{\tilde{t}}, \theta_{\tilde{t}}\right) \mid g_{t}=\ell, \sigma^{*}\right]-\mathbb{E}\left[\sum_{\tilde{t}=t+1}^{\infty} \delta^{(\tilde{t}-t-1)} v\left(g_{\tilde{t}}, \theta_{\tilde{t}}\right) \mid g_{t}=i, \sigma^{*}\right]\right] .
\end{aligned}
$$

Substituting from (3) yields $\mu_{t}\left(m_{t}, c_{t}\right) S \geq L+\delta A\left(\pi, q, L, S, \delta \mid \sigma^{*}\right)$.

Proof of Lemma 2. By Definition 1, in any equilibrium, in period $t$ an illiberal government's optimal censorship policy $c_{t+1}=c^{*}$ is such that: for all censorship policies $c^{\prime}$ and continuation strategies $\sigma^{*}$ (using the law of iterated expectations and noting that period- $t$ deviations do not affect continuation payoffs after period $t+1$ )

$$
\begin{aligned}
& \delta R \operatorname{Pr}\left[g_{t+1}=i \mid c_{t+1}=c^{*}\right]+\mathbb{E}\left[\sum_{\tilde{t}=t+2}^{\infty} \delta^{\tilde{t}-t} R \mathcal{X}\left(\left\{g_{t^{\prime}}\right\}_{t+1}^{\tilde{t}}\right) \mid \sigma^{*}\right] \\
& \geq \delta R \operatorname{Pr}\left[g_{t+1}=i \mid c_{t+1}=c^{\prime}\right]+\mathbb{E}\left[\sum_{\tilde{t}=t+2}^{\infty} \delta^{\tilde{t}-t} R \mathcal{X}\left(\left\{g_{t^{\prime}}\right\}_{t+1}^{\tilde{t}}\right) \mid \sigma^{*}\right] \\
& \Longleftrightarrow \operatorname{Pr}\left[g_{t+1}=i \mid c_{t+1}=c^{*}\right] \geq \operatorname{Pr}\left[g_{t+1}=i \mid c_{t+1}=c^{\prime}\right] .
\end{aligned}
$$

Proof of Lemma 3. We begin by proving that $\bar{A}(\pi, q, L, S, \delta)$ (as defined in (4)) is indeed the maximum accountability cost of illiberalism.

Lemma 4 In equilibrium, $0 \leq A\left(\pi, q, L, S, \delta \mid \sigma^{*}\right)$, and either the illiberal government is indifferent between all censorship policies or

$$
A\left(\pi, q, L, S, \delta \mid \sigma^{*}\right) \leq \bar{A}(\pi, q, L, S, \delta) .
$$

Proof. We begin by proving that $0 \leq A\left(\pi, q, L, S, \delta \mid \sigma^{*}\right)$. By Definition 1 , for any censor- 
ship policy $c_{t}$ and equilibrium assessment $\sigma^{*}$, we have that

$$
\begin{aligned}
& V\left(g_{t}=i \mid \sigma^{*}\right)=\sum_{m^{\prime}=0,1} \operatorname{Pr}\left[m_{t}=m^{\prime} \mid c_{t}\right] \max \left\{L-\mu_{t}^{*}\left(m^{\prime}, c_{t}\right) S+\delta V\left(g_{t}=\ell \mid \sigma^{*}\right), \delta V\left(g_{t}=i \mid \sigma^{*}\right)\right\} \\
& =\sum_{m^{\prime}=0,1} \sum_{s^{\prime}=0,1} \operatorname{Pr}\left[m_{t}=m^{\prime}, s\left(\theta_{t}\right)=s^{\prime} \mid c_{t}\right] \max \left\{L-\mu_{t}^{*}\left(m^{\prime}, c_{t}\right) S+\delta V\left(g_{t}=\ell \mid \sigma^{*}\right), \delta V\left(g_{t}=i \mid \sigma^{*}\right)\right\} \\
& \leq \sum_{m^{\prime}=0,1} \sum_{s^{\prime}=0,1} \operatorname{Pr}\left[m_{t}=m^{\prime}, s\left(\theta_{t}\right)=s^{\prime} \mid c_{t}\right] \max \left\{L-\mu_{t}^{*}\left(s^{\prime}, c_{\ell}\right) S+\delta V\left(g_{t}=\ell \mid \sigma^{*}\right), \delta V\left(g_{t}=i \mid \sigma^{*}\right)\right\} \\
& =\sum_{s^{\prime}=0,1} \operatorname{Pr}\left[s\left(\theta_{t}\right)=s^{\prime} \mid c_{t}\right] \max \left\{L-\mu_{t}^{*}\left(s^{\prime}, c_{\ell}\right) S+\delta V\left(g_{t}=\ell \mid \sigma^{*}\right), \delta V\left(g_{t}=i \mid \sigma^{*}\right)\right\} \\
& =V\left(g_{t}=\ell \mid \sigma^{*}\right),
\end{aligned}
$$

where the inequality follows because any censorship policy is (weakly) less informative than the fully revealing censorship policy, and the final equality follows from the law of iterated expectations.

We now prove the upper bound $A\left(\pi, q, L, S, \delta \mid \sigma^{*}\right) \leq \bar{A}(\pi, q, L, S, \delta)$ when the illiberal government is not indifferent between all censorship policies. By Lemma 2 , there exist a censorship policy $c^{\prime} \neq c^{*}$ such that

$$
\operatorname{Pr}\left[g_{t+1}=i \mid c_{t+1}=c^{*}\right]>\operatorname{Pr}\left[g_{t+1}=i \mid c_{t+1}=c^{\prime}\right]
$$

Therefore, there exists message $m^{\prime}$ that sent with positive probability by $c^{\prime}$ such that the voter elects a liberal government: $\mu_{t}^{*}\left(m^{\prime}, c^{\prime}\right) S<L+\delta A\left(\pi, q, L, S, \delta \mid \sigma^{*}\right)$. Similarly, there exists message $m^{*}$ sent with positive probability by $c^{*}$ such that the voter elects an illiberal government: $\mu_{t}^{*}\left(m^{*}, c^{*}\right) S \geq L+\delta A\left(\pi, q, L, S, \delta \mid \sigma^{*}\right)$. Note that for all censorship policies, $c$, and messages, $m$,

$$
\mu_{t}^{*}\left(0, c_{\ell}\right) \leq \mu_{t}^{*}(m, c) \leq \mu_{t}^{*}\left(1, c_{\ell}\right)
$$

therefore

$$
\mu_{t}^{*}\left(0, c_{\ell}\right) S<L+\delta A\left(\pi, q, L, S, \delta \mid \sigma^{*}\right) \leq \mu_{t}^{*}\left(1, c_{\ell}\right) S
$$

i.e., whenever $g_{t-1}=\ell$ (and hence $c_{t}=c_{\ell}$ ), the voter elects the illiberal government if and 
only if $m_{t}=1$. It follows that

$$
\begin{gathered}
V\left(g_{t}=\ell \mid \sigma^{*}\right)=\operatorname{Pr}\left[m_{t}=0 \mid c_{\ell}\right]\left(L-\mu_{t}^{*}\left(0, c_{\ell}\right) S+\delta V\left(g_{t+1}=\ell \mid \sigma^{*}\right)\right) \\
+\operatorname{Pr}\left[m_{t}=1 \mid c_{\ell}\right] \delta V\left(g_{t+1}=i \mid \sigma^{*}\right) \\
=\operatorname{Pr}\left[s\left(\theta_{t}\right)=0\right]\left(L-\operatorname{Pr}\left[\theta_{t}=1 \mid s\left(\theta_{t}\right)=0\right] S+\delta V\left(g_{t+1}=\ell \mid \sigma^{*}\right)\right) \\
+\operatorname{Pr}\left[s\left(\theta_{t}\right)=1\right] \delta V\left(g_{t+1}=i \mid \sigma^{*}\right) .
\end{gathered}
$$

Because $V\left(g_{t}=i \mid \sigma^{*}\right)=V\left(g_{t+1}=i \mid \sigma^{*}\right)$ and $V\left(g_{t}=\ell \mid \sigma^{*}\right)=V\left(g_{t+1}=\ell \mid \sigma^{*}\right)$, we can recursively substitute (17) into (3):

$$
\begin{gathered}
A\left(\pi, q, L, S, \delta \mid \sigma^{*}\right)=\operatorname{Pr}\left[s\left(\theta_{t}\right)=0\right]\left(L-\operatorname{Pr}\left[\theta_{t}=1 \mid s\left(\theta_{t}\right)=0\right] S+\delta V\left(g_{t}=\ell \mid \sigma^{*}\right)\right) \\
\quad-V\left(g_{t}=i \mid \sigma^{*}\right)\left[1-\delta \operatorname{Pr}\left[s\left(\theta_{t}\right)=1\right]\right] \\
=\operatorname{Pr}\left[s\left(\theta_{t}\right)=0\right]\left(L-\operatorname{Pr}\left[\theta_{t}=1 \mid s\left(\theta_{t}\right)=0\right] S\right) \sum_{\tilde{t}=t}^{\infty} \delta^{\tilde{t}-t} \operatorname{Pr}\left[s\left(\theta_{t}\right)=0\right]^{\tilde{t}-t} \\
\quad-V\left(g_{t}=i \mid \sigma^{*}\right)\left[1-\frac{\delta \operatorname{Pr}\left[s\left(\theta_{t}\right)=1\right]}{1-\delta \operatorname{Pr}\left[s\left(\theta_{t}\right)=0\right]}\right] \\
=\operatorname{Pr}\left[s\left(\theta_{t}\right)=0\right]\left(L-\operatorname{Pr}\left[\theta_{t}=1 \mid s\left(\theta_{t}\right)=0\right] S\right) \frac{1}{1-\delta \operatorname{Pr}\left[s\left(\theta_{t}\right)=0\right]} \\
\quad-V\left(g_{t}=i \mid \sigma^{*}\right)\left[\frac{1-\delta}{1-\delta \operatorname{Pr}\left[s\left(\theta_{t}\right)=0\right]}\right] \\
\leq \bar{A}(\pi, q, L, S, \delta)-V\left(g_{t}=i \mid \sigma^{*}\right)\left[\frac{1-\delta}{1-\delta \operatorname{Pr}\left[s\left(\theta_{t}\right)=0\right]}\right]
\end{gathered}
$$

Therefore, if $V\left(g_{t}=i \mid \sigma^{*}\right) \geq 0$, then the proof is complete. To see this end, we consider two exhaustive cases. First, suppose that, in equilibrium, the illiberal government is able to guarantee its reelection. In this case, it is immediate that $V\left(g_{t}=i \mid \sigma^{*}\right)=0$. Second, suppose otherwise. In this case,

$$
\begin{gathered}
V\left(g_{t}=i \mid \sigma^{*}\right)=\operatorname{Pr}\left[m_{t}=0 \mid c^{*}\right]\left(L-\mu_{t}^{*}\left(0, c^{*}\right) S+\delta V\left(g_{t+1}=\ell \mid \sigma^{*}\right)\right) \\
+\operatorname{Pr}\left[m_{t}=1 \mid c^{*}\right] \delta V\left(g_{t+1}=i \mid \sigma^{*}\right) .
\end{gathered}
$$

However, in equilibrium the voter elects the liberal government if and only if

$$
L-\mu_{t}^{*}\left(0, c^{*}\right) S+\delta V\left(g_{t+1}=\ell \mid \sigma^{*}\right)>\delta V\left(g_{t+1}=i \mid \sigma^{*}\right) .
$$


Therefore,

$$
\begin{aligned}
V\left(g_{t}=i \mid \sigma^{*}\right) & >\operatorname{Pr}\left[m_{t}=0 \mid c^{*}\right] \delta V\left(g_{t+1}=i \mid \sigma^{*}\right)+\operatorname{Pr}\left[m_{t}=1 \mid c^{*}\right] \delta V\left(g_{t+1}=i \mid \sigma^{*}\right) \\
& =\delta V\left(g_{t+1}=i \mid \sigma^{*}\right) \\
& =\delta V\left(g_{t}=i \mid \sigma^{*}\right) \\
\Longleftrightarrow V\left(g_{t}=i \mid \sigma^{*}\right) & >0
\end{aligned}
$$

We now prove Point 1 of Lemma 3. Suppose that, in equilibrium, the illiberal government is not indifferent between all censorship policies, and $\pi S \geq L+\delta \bar{A}(\pi, q, L, S, \delta) \geq$ $L+\delta A\left(\pi, q, L, S, \delta \mid \sigma^{*}\right)$, where the last inequality follows from Lemma 4 . Therefore, any censorship policy such that

$$
\mu_{t}^{*}\left(m_{t}, c^{*}\right) S \geq L+\delta \bar{A}(\pi, q, L, S, \delta) \quad \forall m_{t}
$$

guarantees reelection and is optimal for the illiberal government; because

$$
\mu_{t}^{*}\left(m_{t}, c_{F}\right) \equiv \operatorname{Pr}\left[\theta_{t}=1 \mid m_{t}, c_{F}\right]=\pi \quad \forall m_{t}
$$

this includes the full censorship policy, $c_{F}$. We now show that any censorship policy that violates (20) is not optimal for the illiberal government. By contradiction, suppose that there is a censorship policy $c^{\prime}$ that does not satisfy (20) but guarantees the illiberal government's reelection. Then there exists $m$ such that

$$
L+\delta \bar{A}(\pi, q, L, S, \delta)>\mu_{t}^{*}\left(m, c^{\prime}\right) S \geq L+\delta A\left(\pi, q, L, S, \delta \mid \sigma^{*}\right)
$$

and $V\left(g_{t}=i \mid \sigma^{*}\right)=0$. Furthermore, by (19)

$$
A\left(\pi, q, L, S, \delta \mid \sigma^{*}\right)=\operatorname{Pr}\left[s\left(\theta_{t}\right)=0\right]\left(L-\operatorname{Pr}\left[\theta_{t}=1 \mid s\left(\theta_{t}\right)=0\right] S\right) \frac{1}{1-\delta \operatorname{Pr}\left[s\left(\theta_{t}\right)=0\right]} .
$$

Since, by Lemma $4, A\left(\pi, q, L, S, \delta \mid \sigma^{*}\right) \geq 0$ (and therefore $L-\operatorname{Pr}\left[\theta_{t}=1 \mid s\left(\theta_{t}\right)=0\right] S<0$ ), then $A\left(\pi, q, L, S, \delta \mid \sigma^{*}\right)=\bar{A}(\pi, q, L, S, \delta)$, which contradicts (21).

We now prove Point 2 of Lemma 3. Suppose that, in equilibrium, the illiberal government is not indifferent between all censorship policies, and

$$
\pi S<L+\delta \bar{A}(\pi, q, L, S, \delta)
$$


As was shown in the proof of Lemma 4 , this implies that if $c_{t}=c_{\ell}$, then the illiberal government is elected if and only if $m_{t}=1$. Hence, in equilibrium, the illiberal government must be reelected with positive probability that is no less than $\operatorname{Pr}\left[m_{t}=1 \mid c_{\ell}\right]=\operatorname{Pr}\left[s\left(\theta_{t}\right)=\right.$ 1].

We now show that the illiberal government cannot guarantee its reelection with any censorship policy. By contradiction, suppose that the illiberal government can guarantee its reelection by choosing some censorship policy $c^{*}$. Then, as shown in proving Point 1, $A\left(\pi, q, L, S, \delta \mid \sigma^{*}\right)=\bar{A}(\pi, q, L, S, \delta)$. Therefore, it must be that $\mu_{t}^{*}\left(m_{t}, c^{*}\right) S \geq L+$ $\delta \bar{A}(\pi, q, L, S, \delta)$ for all $m_{t}$, and, hence, in equilibrium,

$$
\begin{gathered}
\sum_{m=0,1} \operatorname{Pr}\left[m_{t}=m \mid c^{*}\right] \mu_{t}^{*}\left(m, c^{*}\right) S \geq \sum_{m=0,1} \operatorname{Pr}\left[m_{t}=m \mid c^{*}\right](L+\delta \bar{A}(\pi, q, L, S, \delta)) \\
\Longleftrightarrow \operatorname{Pr}\left[\theta_{t}=1\right] S=\pi S \geq L+\delta \bar{A}(\pi, q, L, S, \delta)
\end{gathered}
$$

which contradicts (22).

So far we have shown that the illiberal government is reelected with probability strictly between 0 and 1 , which also implies that the full censorship policy, $c_{F}$, is not chosen in equilibrium: $c^{*}(0)<c^{*}(1)$. Therefore,

$$
\mu_{t}^{*}\left(0, c^{*}\right)<\pi<\mu_{t}^{*}\left(1, c^{*}\right)
$$

By (3) and (22), the voter does not elect the illiberal government upon observing $m_{t}=0$. Therefore, the illiberal government's problem is

$$
\begin{array}{ll} 
& \max _{c: c(0)<c(1)}\left\{c(1) \operatorname{Pr}\left[s\left(\theta_{t}\right)=1\right]+c(0) \operatorname{Pr}\left[s\left(\theta_{t}\right)=0\right]\right\} \\
\text { s.t. } & \mu_{t}^{*}(1, c) S \geq L+\delta A\left(\pi, q, L, S, \delta \mid \sigma^{*}\right)
\end{array}
$$

Notice that $\mu_{t}^{*}(1, c)$ is strictly increasing in $c(1)$ and strictly decreasing in $c(0)$. Therefore, (i) $c^{*}(1)=1$ and (ii) the constraint is binding.

For a given set of parameters, our model allows for a multiplicity of equilibria. However, the equilibrium is essentially unique in the following sense. Two equilibria are essentially equivalent if, for any $t$ and any $g_{t-1}$, the probability that an illiberal government is elected is equal in each equilibrium (and hence the voter's and illiberal government's expected payoffs are also equal). For any given set of parameters, we say that the equilibrium is essentially unique if all equilibria are essentially equivalent.

In Supplementary Material we prove the following lemma. 
Lemma 5 (Essentially unique equilibrium.) For any given set of parameters, the equilibrium is essentially unique.

Proof of Proposition 1. Suppose $L>\mu_{t}^{*}\left(1, c_{\ell}\right) S$. Because the equilibrium is essentially unique (Lemma 5), it suffices to show that $\sigma^{*}=\left(g^{*}, c^{*},\left\{\mu_{t}^{*}\right\}_{t=1}^{\infty}\right)$ such that

$$
g^{*}\left(m_{t}, c_{t}\right)=i \Longleftrightarrow \mu_{t}^{*}\left(m_{t}, c_{t}\right) S \geq L
$$

and $c^{*}$ is any censorship policy is an equilibrium and that it induces $g_{t}=\ell$ for all $t \geq 1$.

That $\sigma^{*}$ induces $g_{t}=\ell$ for all $t \geq 1$ follows by Lemma 1 because, for all censorship policies $c_{t}$ and any message $m_{t}^{\prime}$ that is sent with positive probability under $c_{t}$,

$$
\mu_{t}^{*}\left(m_{t}^{\prime}, c_{t}\right) S \leq \mu_{t}^{*}\left(1, c_{\ell}\right) S<L
$$

We now show that $\sigma^{*}$ is an equilibrium. Because $g_{t}=\ell$ for all $t, A\left(\pi, q, L, S, \delta \mid \sigma^{*}\right)=$ 0 , then Lemma 1 implies that $g^{*}$ is the voter's equilibrium strategy. Condition (ii) in Definition 1 is trivially satisfied because the illiberal government is indifferent between all censorship policies (see (24)). Finally, Condition (iii) is satisfied because the voter's beliefs were constructed via Bayes' rule.

Proof of Proposition 2. Suppose $L \leq \mu_{t}^{*}\left(0, c_{\ell}\right) S$. Because the equilibrium is essentially unique (Lemma 5), it suffices to show that $\sigma^{*}=\left(g^{*}, c^{*},\left\{\mu_{t}^{*}\right\}_{t=1}^{\infty}\right)$ such that

$$
g^{*}\left(m_{t}, c_{t}\right)=i \Longleftrightarrow \mu_{t}^{*}\left(m_{t}, c_{t}\right) S \geq L,
$$

and $c^{*}$ is any censorship policy is an equilibrium and that it induces $g_{t}=i$ for all $t \geq 1$.

That $\sigma^{*}$ induces $g_{t}=i$ for all $t \geq 1$ follows by Lemma 1 because, for all censorship policies $c_{t}$ and any message $m_{t}^{\prime}$ that is sent with positive probability under $c_{t}$,

$$
\mu_{t}^{*}\left(m_{t}^{\prime}, c_{t}\right) S \geq \mu_{t}^{*}\left(0, c_{\ell}\right) S \geq L
$$

We now show that $\sigma^{*}$ is an equilibrium. Because $g_{t}=i$ for all $t, A\left(\pi, q, L, S, \delta \mid \sigma^{*}\right)=$ 0 , then Lemma 1 implies that $g^{*}$ is the voter's equilibrium strategy. Condition (ii) in Definition 1 is trivially satisfied because the illiberal government is indifferent between all censorship policies (see (26)). Finally, Condition (iii) is satisfied because the voter's beliefs were constructed via Bayes' rule. 
Proof of Proposition 3. Suppose

$$
\mu_{t}^{*}\left(0, c_{\ell}\right) S<L \quad \text { and } \quad L \leq \pi S-\delta \bar{A}(\pi, q, L, S, \delta) .
$$

Because the equilibrium is essentially unique (Lemma 5), it suffices to show that $\sigma^{*}=$ $\left(g^{*}, c^{*},\left\{\mu_{t}^{*}\right\}_{t=1}^{\infty}\right)$ such that

$$
g^{*}\left(m_{t}, c_{t}\right)=i \Longleftrightarrow \mu_{t}^{*}\left(m_{t}, c_{t}\right) S \geq L+\delta \bar{A}(\pi, q, L, S, \delta),
$$

and

$$
\mu_{t}^{*}\left(m_{t}, c^{*}\right) S \geq L+\delta \bar{A}(\pi, q, L, S, \delta) \quad \forall m_{t}
$$

is an equilibrium and

1. under a liberal government $\left(g_{t-1}=\ell\right.$ and hence $\left.c_{t}=c_{\ell}\right)$, the voter elects an illiberal government if and only if $m_{t}=1$; and

2. once an illiberal government has been elected $\left(g_{t-1}=i\right)$ and chooses $c^{*}$, the voter reelects the illiberal government with probability one.

Starting with Point 1 , by (27) and because $\bar{A}(\pi, q, L, S, \delta) \geq 0$ by (4), we have

$$
\operatorname{Pr}\left[\theta_{t}=1 \mid m_{t}=0, c_{\ell}\right] S<L+\delta \bar{A}(\pi, q, L, S, \delta) \leq \pi S
$$

Furthermore, $\pi<\operatorname{Pr}\left[\theta_{t}=1 \mid m_{t}=1, c_{\ell}\right]$. Therefore, $g^{*}$ implies that Point 1 holds.

Turning to Point 2. Combining (28) and (29), it is immediate that the illiberal government is reelected with probability one in equilibrium.

We now show that $\sigma^{*}$ is an equilibrium. Because of (27) and Point 1 and 2, the accountability cost of illiberalism, $A\left(\pi, q, L, S, \delta \mid \sigma^{*}\right)$, is maximal:

$$
\begin{aligned}
& \sum_{\tilde{t}=t+1}^{\infty}\left(\delta \operatorname{Pr}\left[s\left(\theta_{\tilde{t}}\right)=0\right]\right)^{\tilde{t}-(t+1)} \operatorname{Pr}\left[s\left(\theta_{\tilde{t}}\right)=0\right]\left(L-\operatorname{Pr}\left[\theta_{\tilde{t}}=1 \mid s\left(\theta_{\tilde{t}}\right)=0\right] S\right) \\
& =\frac{\operatorname{Pr}\left[s\left(\theta_{t}\right)=0\right]}{1-\delta \operatorname{Pr}\left[s\left(\theta_{t}\right)=0\right]}\left(L-\operatorname{Pr}\left[\theta_{t}=1 \mid s\left(\theta_{t}\right)=0\right] S\right) \\
& =\bar{A}(\pi, q, L, S, \delta)
\end{aligned}
$$

Then Lemma 1 implies that $g^{*}$ is the voter's equilibrium strategy. If there exists a censorship policy satisfying (29), then Condition (ii) of Definition 1 is trivially satisfied because 
it implies that the illiberal government is reelected with probability 1 . It immediate that such a censorship policy exists-namely, the full censorship policy $c_{F}$. This is because $c_{F}$ always induces belief $\mu_{t}^{*}\left(m_{t}, c_{F}\right)=\operatorname{Pr}\left[s\left(\theta_{t}\right)=1\right]=\pi$ and (27) holds. Finally, Condition (iii) is satisfied because the voter's beliefs were constructed via Bayes' rule.

Proof of Proposition 4. Suppose

$$
\pi S-\delta \bar{A}(\pi, q, L, S, \delta)<L \quad \text { and } \quad L \leq \mu_{t}^{*}\left(1, c_{\ell}\right) S
$$

Because the equilibrium is essentially unique (Lemma 5), it suffices to show that $\sigma^{*}=$ $\left(g^{*}, c^{*},\left\{\mu_{t}^{*}\right\}_{t=1}^{\infty}\right)$ such that

$$
g^{*}\left(m_{t}, c_{t}\right)=i \Longleftrightarrow \mu_{t}^{*}\left(m_{t}, c_{t}\right) S \geq L+\delta \operatorname{Pr}\left[s\left(\theta_{t}\right)=1\right] \frac{\mu_{t}^{*}\left(1, c_{\ell}\right) S-L}{1+\delta \operatorname{Pr}\left[s\left(\theta_{t}\right)=1\right]},
$$

$c^{*}(0)<1=c^{*}(1)$, and

$$
\mu_{t}^{*}\left(1, c^{*}\right) S=L+\delta \operatorname{Pr}\left[s\left(\theta_{t}\right)=1\right] \frac{\mu_{t}^{*}\left(1, c_{\ell}\right) S-L}{1+\delta \operatorname{Pr}\left[s\left(\theta_{t}\right)=1\right]},
$$

is an equilibrium, and it induces the voter to elect an illiberal government if and only if $m_{t}=1$ for any $g_{t-1}$.

That $\sigma^{*}$ induces $g_{t}=i$ if and only if $m_{t}=1$ follows by (31) and (32) and because

$$
\mu_{t}^{*}\left(0, c_{\ell}\right)<\mu_{t}^{*}\left(0, c^{*}\right)<\mu_{t}^{*}\left(1, c^{*}\right)<\mu_{t}^{*}\left(1, c_{\ell}\right)
$$

We now show that $\sigma^{*}$ is an equilibrium. First, we show that

$$
A\left(\pi, q, L, S, \delta \mid \sigma^{*}\right)=\operatorname{Pr}\left[s\left(\theta_{t}\right)=1\right] \frac{\mu_{t}^{*}\left(1, c_{\ell}\right) S-L}{1+\delta \operatorname{Pr}\left[s\left(\theta_{t}\right)=1\right]} .
$$

Because $\sigma^{*}$ induces $g_{t}=i$ if and only if $m_{t}=1$, the voter's continuation payoffs are such that

$$
\begin{aligned}
V\left(g_{t}=\ell \mid \sigma^{*}\right)=\operatorname{Pr}[ & \left.s\left(\theta_{t}\right)=1\right] \delta V\left(g_{t}=i \mid \sigma^{*}\right) \\
& +\operatorname{Pr}\left[s\left(\theta_{t}\right)=0\right]\left(L-\operatorname{Pr}\left[\theta_{t}=1 \mid s\left(\theta_{t}\right)=0\right] S+\delta V\left(g_{t}=\ell \mid \sigma^{*}\right)\right),
\end{aligned}
$$


and

$$
\begin{aligned}
V\left(g_{t}=i \mid \sigma^{*}\right)=( & \left.\operatorname{Pr}\left[s\left(\theta_{t}\right)=1\right]+c^{*}(0) \operatorname{Pr}\left[s\left(\theta_{t}\right)=0\right]\right) \delta V\left(g_{t}=i \mid \sigma^{*}\right) \\
& +\left(1-c^{*}(0)\right) \operatorname{Pr}\left[s\left(\theta_{t}\right)=0\right]\left(L-\mu_{t}^{*}\left(0, c^{*}\right) S+\delta V\left(g_{t}=\ell \mid \sigma^{*}\right)\right) .
\end{aligned}
$$

The value of $c^{*}(0)$ is implicitly defined in (32), i.e., $c^{*}(0)$ satisfies

$$
\begin{aligned}
& \frac{\pi q+c^{*}(0) \pi(1-q)}{\operatorname{Pr}\left[s\left(\theta_{t}\right)=1\right]+c^{*}(0) \operatorname{Pr}\left[s\left(\theta_{t}\right)=0\right]} S=L+\delta \operatorname{Pr}\left[s\left(\theta_{t}\right)=1\right] \frac{\mu_{t}^{*}\left(1, c_{\ell}\right) S-L}{1+\delta \operatorname{Pr}\left[s\left(\theta_{t}\right)=1\right]} \\
& \Longleftrightarrow c^{*}(0)=\frac{L \operatorname{Pr}\left[s\left(\theta_{t}\right)=1\right]-\pi q S}{\pi(1-q-\delta(1-\pi)(2 q-1)) S-L \operatorname{Pr}\left[s\left(\theta_{t}\right)=0\right]} .
\end{aligned}
$$

Subtracting (34) from (35) and simplifying yields the accountability cost of illiberalism:

$$
A\left(\pi, q, L, S, \delta \mid \sigma^{*}\right)=\frac{c^{*}(0) \operatorname{Pr}\left[s\left(\theta_{t}\right)=0\right]\left(L-\operatorname{Pr}\left[\theta_{t}=1 \mid s\left(\theta_{t}\right)=0\right] S\right)}{1-c^{*}(0) \delta \operatorname{Pr}\left[s\left(\theta_{t}\right)=0\right]}
$$

which, after substituting (36), yields (33). Then Lemma 1 implies that $g^{*}$ is the voter's equilibrium strategy.

Now consider condition (ii). By Lemma 3 and (33), the censorship policy $c^{*}$ described in (32) must be optimal for the illiberal government. However, it remains to prove that there exists such a censorship policy, i.e., we must show that $c^{*}(0) \in[0,1)$. First, note that the left hand side of (32) is continuous in $c^{*}(0)$; strictly decreasing with $c^{*}(0)$; and takes maximum and minimum values of $\operatorname{Pr}\left[\theta_{t}=1 \mid s\left(\theta_{t}\right)=1\right] S$ and $\pi S$ at $c^{*}(0)=0$ and $c^{*}(0)=1$, respectively. Second, note that the right hand side is constant in $c^{*}(0)$. Therefore, by the Intermediate Value Theorem, it suffices to show that the right hand side of (32) takes a value in the interval

$$
\left(\pi S, \operatorname{Pr}\left[\theta_{t}=1 \mid s\left(\theta_{t}\right)=1\right] S\right]
$$

To see this, we rearrange the right hand side of (32) as

$$
\frac{L+\delta \operatorname{Pr}\left[s\left(\theta_{t}\right)=1\right] \mu_{t}^{*}\left(1, c_{\ell}\right) S}{1+\delta \operatorname{Pr}\left[s\left(\theta_{t}\right)=1\right]}
$$

We show that (38) is bound between $\pi S$ and $\mu_{t}^{*}\left(1, c_{\ell}\right) S$. Because (30) places an upper bound on $L$, the value (38) is no larger than $\mu_{t}^{*}\left(1, c_{\ell}\right) S$. Condition (30) also places a lower 
bound on $L$. Substituting the explicit form of $\bar{A}(\pi, q, L, S, \delta)$ into (30) yields

$$
\pi S\left(1-\delta \operatorname{Pr}\left[s\left(\theta_{t}\right)=0\right]\right)+\delta \operatorname{Pr}\left[s\left(\theta_{t}\right)=0\right] \operatorname{Pr}\left[\theta_{t}=1 \mid s\left(\theta_{t}\right)=0\right] S<L .
$$

Finally, substituting (39) into (38) proves the lower bound:

$$
\frac{L+\delta \operatorname{Pr}\left[s\left(\theta_{t}\right)=1\right] \mu_{t}^{*}\left(1, c_{\ell}\right) S}{1+\delta \operatorname{Pr}\left[s\left(\theta_{t}\right)=1\right]}>\frac{\pi S\left(1-\delta \operatorname{Pr}\left[s\left(\theta_{t}\right)=0\right]\right)+\delta \pi S}{1+\delta \operatorname{Pr}\left[s\left(\theta_{t}\right)=1\right]}=\pi S .
$$

Condition (iii) is satisfied because the voter's beliefs were constructed via Bayes' rule.

Proof of Proposition 5. Follows from Proposition 10.

Proposition 10 There exist cutoffs

$$
\begin{aligned}
\underline{\kappa}(\pi, q) & :=\mu_{t}^{*}\left(0, c_{\ell}\right), \\
\kappa(\pi, q ; \delta) & :=\pi(1-\delta(1-\pi)(2 q-1)), \\
\bar{\kappa}(\pi, q) & :=\mu_{t}^{*}\left(1, c_{\ell}\right),
\end{aligned}
$$

such that $0<\underline{\kappa}(\pi, q)<\kappa(\pi, q ; \delta)<\bar{\kappa}(\pi, q)<1$ and, in equilibrium, a constitution with

1. $\bar{L} \leq \underline{\kappa}(\pi, q)$ induces an efficient stable illiberal democracy;

2. $\bar{L} \in(\underline{\kappa}(\pi, q), \kappa(\pi, q ; \delta)]$ induces an inefficient stable illiberal democracy;

3. $\bar{L} \in(\kappa(\pi, q ; \delta), \bar{\kappa}(\pi, q)]$ induces a cycling liberal-illiberal democracy; and

4. $\bar{L}>\bar{\kappa}(\pi, q)$ induces an efficient stable liberal democracy.

Proof of Proposition 10. From Propositions 1, 2, 3, and 4, an efficient stable liberal democracy occurs if $\mu_{t}^{*}\left(1, c_{\ell}\right)<\bar{L}$; an efficient stable illiberal democracy occurs if $\bar{L} \leq$ $\mu_{t}^{*}\left(0, c_{\ell}\right)$; an inefficient stable illiberal democracy occurs if

$$
\mu_{t}^{*}\left(0, c_{\ell}\right)<\bar{L} \quad \text { and } \quad L \leq \pi S-\delta \bar{A}(\pi, q, L, S, \delta)
$$

a cycling liberal-illiberal democracy occurs if

$$
\pi S-\delta \bar{A}(\pi, q, L, S, \delta)<L \quad \text { and } \quad \bar{L} \leq \mu_{t}^{*}\left(1, c_{\ell}\right)
$$

Substituting (4) into the second inequality of (43) and noticing that the first inequality in (43) implies that $\bar{A}(\pi, q, L, S, \delta)>0$ yields $\bar{L} \leq \pi(1-\delta(1-\pi)(2 q-1))$. Also the first 
inequality in (44) simplifies to

$$
\bar{L}> \begin{cases}\pi & \text { if } \bar{L}<\operatorname{Pr}\left[\theta_{t}=1 \mid s\left(\theta_{t}\right)=0\right], \\ \pi(1-\delta(1-\pi)(2 q-1)) & \text { otherwise. }\end{cases}
$$

However, the first case in (45) cannot occur because $\operatorname{Pr}\left[\theta_{t}=1 \mid s\left(\theta_{t}\right)=0\right]>\pi$. Therefore, (43) and (44) simplify to

$$
\mu_{t}^{*}\left(0, c_{\ell}\right)<\bar{L} \leq \pi(1-\delta(1-\pi)(2 q-1))
$$

and

$$
\pi(1-\delta(1-\pi)(2 q-1))<\bar{L} \leq \mu_{t}^{*}\left(1, c_{\ell}\right),
$$

respectively. Defining $\underline{\kappa}(\pi, q), \kappa(\pi, q ; \delta)$, and $\bar{\kappa}(\pi, q)$ as in (40), (41), and (42) and noting that $0<\underline{\kappa}(\pi, q)<\kappa(\pi, q ; \delta)<\bar{\kappa}(\pi, q)<1$, completes the proof.

Proof of Proposition 6. For $\pi$. If $\bar{L} \geq 1$, then an efficient stable liberal democracy occurs for all values of $\pi \in(0,1)$, and the illiberal government is elected with probability 0 for all $\pi$. Thus, the proposition statement trivially holds. Now suppose that $\bar{L} \in(0,1)$. Recall from Proposition 10 that

$$
0<\underline{\kappa}(\pi, q)<\kappa(\pi, q ; \delta)<\bar{\kappa}(\pi, q)<1 \quad \forall \pi \in(0,1) .
$$

These thresholds are all continuous and strictly increasing with $\pi$. Furthermore, in the limiting cases $\pi=0$ and $\pi=1$, we have

$$
0=\underline{\kappa}(0, q)=\kappa(0, q ; \delta)=\bar{\kappa}(0, q) \quad \text { and } \quad 1=\underline{\kappa}(1, q)=\kappa(1, q ; \delta)=\bar{\kappa}(1, q) .
$$

Combing these observations, implies the following lemma.

Lemma 6 There exists three values $0<\pi_{1}<\pi_{2}<\pi_{3}<1$ such that

1. if $\pi<\pi_{1}$, an efficient stable liberal democracy occurs, and if $g_{t-1}=\ell$, the illiberal government is elected with probability 0 ;

2. if $\pi_{1} \leq \pi<\pi_{2}$ or $\pi_{2} \leq \pi<\pi_{3}$, a cycling liberal-illiberal democracy or an inefficient stable illiberal democracy occurs. In either case, if $g_{t-1}=\ell$, the illiberal government is elected with probability $\operatorname{Pr}\left[s\left(\theta_{t}\right)=1\right]=\pi q+(1-\pi)(1-q)$, which is strictly increasing with $\pi$;

3. if $\pi_{3} \leq \pi$, an efficient stable illiberal democracy occurs, and if $g_{t-1}=\ell$, an efficient stable illiberal democracy occurs, and the illiberal government is elected with probability 1. 
For $\bar{L}$. From Proposition 10, as $\bar{L}$ increases from 0 , the regime transitions from an efficient stable illiberal, inefficient stable illiberal, cycling liberal-illiberal to an efficient stable liberal democracy. Therefore, when $g_{t-1}=\ell$, the illiberal government's election probability transitions from 1 to $\operatorname{Pr}\left[s\left(\theta_{t}\right)=1\right]$ and then to 0 . Because $\operatorname{Pr}\left[s\left(\theta_{t}\right)=1\right]$ is constant in $\bar{L}$, the illiberal government's election probability is weakly decreasing in $\bar{L}$.

For $q$. If $\bar{L} \geq 1$, then an efficient stable liberal democracy occurs for all values of $q \in$ $(1 / 2,1)$, and the illiberal government is elected with probability 0 for all $\pi$. Thus, the proposition statement holds.

Now suppose that $\bar{L}<\pi$. In this case, an efficient stable liberal democracy will never arise because $\pi<\bar{\kappa}(\pi, q)$ for all $q \in(1 / 2,1)$ (Proposition 10). We now show that there is a unique value $\underline{q}$ such that $\bar{L}=\underline{\kappa}(\pi, q)$ : for all $q \leq \underline{q}$, an efficient stable illiberal democracy occurs; for $q>\underline{q}$, either a cycling liberal-illiberal or an inefficient stable illiberal democracy will occur. This will complete Part 2 and 4 of the proposition statement because, when $g_{t-1}=\ell$, the illiberal government's election probability will transition from 1 to

$$
\operatorname{Pr}\left[s\left(\theta_{t}\right)=1\right]=\pi q+(1-\pi)(1-q)=1-\pi+q(2 \pi-1),
$$

which is strictly increasing with $q$ if $\pi>1 / 2$ and strictly decreasing with $q$ if $\pi<1 / 2$. To show the existence of $\underline{q}$ notice that $\underline{\kappa}(\pi, q)$ is continuous and decreasing with $q \in(1 / 2,1)$, and in the limiting cases of $q=1 / 2$ and $q=1$, takes maximum and minimum values of $\pi$ and 0 , respectively. Therefore, $\underline{\kappa}(\pi, q)$ ranges from 0 to $\pi$ and $\bar{L} \in(0, \pi)$, and so there is a unique value of $\underline{q} \in(1 / 2,1)$ such that $\bar{L}=\underline{\kappa}(\pi, \underline{q})$.

Now suppose that $\bar{L}>\pi$. In this case, neither an efficient stable illiberal democracy nor an inefficient stable illiberal democracy will occur because $\underline{\kappa}(\pi, q)<\kappa(\pi, q ; \delta)<\pi$ for all $q \in(1 / 2,1)$ (Proposition 10). We now prove Lemma 7.

Lemma 7 There exists a unique value $\bar{q}$ such that $\bar{L}=\bar{\kappa}(\pi, \bar{q})$ : for all $q<\bar{q}$, an efficient stable liberal democracy occurs; for $q \geq \bar{q}$, a cycling liberal-illiberal occurs.

Proof. Notice that $\bar{\kappa}(\pi, q)$ is continuous and increasing with $q \in(1 / 2,1)$ and, in the limiting cases of $q=1 / 2$ and $q=1$, takes maximum and minimum values of 1 and $\pi$, respectively. Therefore, $\bar{\kappa}(\pi, q)$ ranges from $\pi$ and 1 and $\bar{L} \in(\pi, 1)$, and so there is a unique value of $\bar{q} \in(1 / 2,1)$ such that $\bar{L}=\bar{\kappa}(\pi, \bar{q})$.

This completes Part 1 and 3 of the proposition because, when $g_{t-1}=\ell$, the illiberal government's election probability will transition from 0 to

$$
\operatorname{Pr}\left[s\left(\theta_{t}\right)=1\right]=\pi q+(1-\pi)(1-q)=1-\pi+q(2 \pi-1),
$$


which is strictly increasing with $q$ if $\pi>1 / 2$ and strictly decreasing with $q$ if $\pi<1 / 2$.

Proof of Proposition 7. If $\bar{L}>1$, then a stable liberal democracy occurs and the illiberal government is elected with probability 0 . We use the cutoffs $\pi_{1}, \pi_{2}, \pi_{3}$ from Lemma 6 . If $\pi<\pi_{1}$, then the illiberal government is elected with probability 0 . Therefore, the proposition only applies when $\pi \geq \pi_{1}$ and $\bar{L} \leq 1$.

For $\pi$. For $\pi \in\left[\pi_{1}, \pi_{2}\right)$, a cycling liberal-illiberal democracy occurs and, by (36), we have

$$
\begin{aligned}
c^{*}(0) & =\frac{L \operatorname{Pr}\left[s\left(\theta_{t}\right)=1\right]-\pi q S}{\pi(1-q-\delta(1-\pi)(2 q-1)) S-L \operatorname{Pr}\left[s\left(\theta_{t}\right)=0\right]} \\
& =\frac{\bar{L}(\pi q+(1-\pi)(1-q))-\pi q}{\pi(1-q-\delta(1-\pi)(2 q-1))-\bar{L}(\pi(1-q)+(1-\pi) q)} .
\end{aligned}
$$

The derivative of (46) with respect to $\pi$ is

$$
\frac{\partial c^{*}(0)}{\partial \pi}=-\frac{(2 q-1)\left(\bar{L}\left(-1+\bar{L}-\delta(1-\pi)^{2}\right)+\delta\left(\bar{L}-2 \bar{L}(1-\pi) \pi-\pi^{2}\right) q\right)}{(\pi(1+\delta(1-\pi)-\bar{L})-(1+2 \delta(1-\pi)) \pi q+\bar{L}(2 \pi-1) q)^{2}} .
$$

This derivative is non-negative if and only if

$$
\delta\left(\bar{L}-2 \bar{L}(1-\pi) \pi-\pi^{2}\right) q \leq \bar{L}\left(1-\bar{L}+\delta(1-\pi)^{2}\right) .
$$

If the LHS of (47) is non-positive, the inequality holds because $\bar{L} \leq 1$ and, hence, the right hand side is positive. Otherwise, the left hand side of (47) is positive. Therefore,

$$
\begin{aligned}
\delta\left(\bar{L}-2 \bar{L}(1-\pi) \pi-\pi^{2}\right) q & <\delta\left(\bar{L}-2 \bar{L}(1-\pi) \pi-\pi^{2}\right) \\
& \leq \bar{L}\left(1-\bar{L}+\delta(1-\pi)^{2}\right)
\end{aligned}
$$

where the first inequality follows from $q<1$ and the last follows if and only if $0 \leq$ $\bar{L}-\bar{L}^{2}+\pi^{2}(1-\delta \bar{L})$, which is true for all $\bar{L} \leq 1$. We conclude that $\frac{\partial c^{*}(0)}{\partial \pi} \geq 0$.

For $\pi \geq \pi_{2}$, either an inefficient stable illiberal democracy occurs or an efficient stable illiberal democracy occurs; in either case, we have $c^{*}(0)=1$.

For $\bar{L}$. For $\bar{L} \in(\kappa(\pi, q ; \delta), \bar{\kappa}(\pi, q)]$, a cycling liberal-illiberal democracy occurs and $c^{*}(0)$ is given by (46). The derivative of (46) with respect to $\bar{L}$ is

$$
\frac{\partial c^{*}(0)}{\partial \bar{L}}=\frac{-(1-\pi) \pi(2 q-1)(1+\delta(\pi q+(1-\pi)(1-q)))}{(\pi(1+\delta-\bar{L}-\delta \pi)-(1+2 \delta(1-\pi)) \pi q+\bar{L}(2 \pi-1) q)^{2}} \leq 0 .
$$

For $\bar{L} \leq \kappa(\pi, q ; \delta)$, either an efficient stable illiberal democracy occurs or an inefficient 
stable illiberal democracy occurs; in either case, $c^{*}(0)=1$.

For q. For $\pi<\bar{L} \leq 1$, because

$$
0<\underline{\kappa}(\pi, q)<\kappa(\pi, q ; \delta)<\pi<\bar{L} \quad \forall q \in(1 / 2,1),
$$

only an efficient stable liberal democracy or a cycling liberal-illiberal democracy can occur. Furthermore, using the threshold in Lemma 7, if $q<\bar{q}$, the illiberal government is never elected and, therefore, the proposition does not apply. Otherwise, $q \geq \bar{q}$ and the amount of censorship, $c^{*}(0)$, is given by (46). Taking the first derivative with respect to $q$ yields

$$
\frac{\partial c^{*}(0)}{\partial q}=\frac{(\bar{L}-\pi)((1-\bar{L}+\delta(1-\pi)) \pi+\bar{L}(1-\pi))}{(\pi(1-\bar{L}+\delta(1-\pi))-(1+2 \delta(1-\pi)) \pi q+\bar{L}(2 \pi-1) q)^{2}},
$$

which is positive because $\pi<\bar{L} \leq 1$.

For $\bar{L}<\pi$, because $\bar{L}<\pi<\bar{\kappa}(\pi, q)$ for all $q \in(1 / 2,1)$, an efficient stable liberal democracy will never occur. We prove the following lemma.

Lemma 8 There exists a unique value $\hat{q}$ such that $\bar{L}=\kappa(\pi, \hat{q} ; \delta)$ : if $q \leq \hat{q}$, an efficient or inefficient stable illiberal democracy occurs; if $q>\hat{q}$, a cycling liberal-illiberal democracy occurs.

Proof. Notice that

$$
\underline{\kappa}(\pi, q), \kappa(\pi, q ; \delta): 0<\underline{\kappa}(\pi, q)<\kappa(\pi, q ; \delta)<\pi \quad \forall q \in(1 / 2,1)
$$

are continuous and decreasing with $q$. Furthermore, in the limiting cases of $q=1 / 2$, $\kappa(\pi, q ; \delta)=\pi(1-\delta(1-\pi)(2 q-1))$ takes a maximum value of $\pi$. Hence, as $q$ increases from $1 / 2, \kappa(\pi, q ; \delta)$ decreases continuously and at linear rate from $\pi$ and $\bar{L} \in(0, \pi)$. Therefore, there is a unique value $\hat{q}$ (possibly exceeding 1 ) such that $\bar{L}=\kappa(\pi, \hat{q} ; \delta)$.

Lemma 8 suffices to prove Part 2 of the proposition because, if $q \leq \hat{q}$, then $c^{*}(0)$ is equal to 1 ; and if $q>\hat{q}$, then $c^{*}(0)$ is given by (46), which is decreasing with $q$ for $\bar{L}<\pi$ (see (50)).

Proof of Proposition 8. If $\bar{L}>1$, then a stable liberal democracy occurs and the illiberal government is elected with probability 0 . We use the cutoffs $\pi_{1}, \pi_{2}, \pi_{3}$ from Lemma 6 . If $\pi<\pi_{1}$, then the illiberal government is elected with probability 0 . Therefore, the proposition only applies when $\pi \geq \pi_{1}$ and $\bar{L} \leq 1$.

For $\pi$. For $\pi \in\left[\pi_{1}, \pi_{2}\right)$, a cycling liberal-illiberal democracy occurs and the illiberal 
government's reelection probability is

$$
\operatorname{Pr}\left[m_{t}=1 \mid c^{*}\right]=\operatorname{Pr}\left[s\left(\theta_{t}\right)=1\right]+c^{*}(0) \operatorname{Pr}\left[s\left(\theta_{t}\right)=0\right],
$$

where $c^{*}(0)$ is given by (36). Taking the derivative (51) with respect to $\pi$

$$
\frac{\partial \operatorname{Pr}\left[m_{t}=1 \mid c^{*}\right]}{\partial \pi}=\left(\frac{\partial \operatorname{Pr}\left[s\left(\theta_{t}\right)=1\right]}{\partial \pi}+c^{*}(0) \frac{\partial \operatorname{Pr}\left[s\left(\theta_{t}\right)=0\right]}{\partial \pi}\right)+\operatorname{Pr}\left[s\left(\theta_{t}\right)=0\right] \frac{\partial c^{*}(0)}{\partial \pi} .
$$

Because

$$
\frac{\partial \operatorname{Pr}\left[s\left(\theta_{t}\right)=1\right]}{\partial \pi}=-\frac{\partial \operatorname{Pr}\left[s\left(\theta_{t}\right)=0\right]}{\partial \pi}=2 q-1>0,
$$

the derivative simplifies to

$$
\frac{\partial \operatorname{Pr}\left[m_{t}=1 \mid c^{*}\right]}{\partial \pi}=(2 q-1)\left(1-c^{*}(0)\right)+\operatorname{Pr}\left[s\left(\theta_{t}\right)=0\right] \frac{\partial c^{*}(0)}{\partial \pi}>0
$$

where the inequality follows because, by Proposition $4, c^{*}(0)<1$ and, by Proposition 7 , $\frac{\partial c^{*}(0)}{\partial \pi} \geq 0$.

For $\pi \geq \pi_{2}$, either an inefficient stable illiberal democracy occurs or an efficient stable illiberal democracy occurs; in either case, the illiberal government is reelected with probability 1.

For $\bar{L}$. For $\bar{\kappa}<\bar{L}$, the illiberal government is elected with probability 0 . Therefore, the proposition does not apply.

For $\bar{L} \in(\kappa(\pi, q ; \delta), \bar{\kappa}(\pi, q)]$, a cycling liberal-illiberal democracy occurs and the reelection probability is given by (51). Taking the derivative of (51) with respect to $\bar{L}$ yields

$$
\frac{\partial \operatorname{Pr}\left[m_{t}=1 \mid c^{*}\right]}{\partial \bar{L}}=\operatorname{Pr}\left[s\left(\theta_{t}\right)=0\right] \frac{\partial c^{*}(0)}{\partial \bar{L}} \leq 0
$$

where the inequality follows because, by Proposition $7, \frac{\partial c^{*}(0)}{\partial \bar{L}} \leq 0$.

For $\bar{L} \leq \kappa(\pi, q ; \delta)$, either an efficient stable illiberal democracy occurs or an inefficient stable illiberal democracy occurs; in either case, the illiberal government's reelection probability 1 .

For q. Suppose $1 / 2<\pi<\bar{L} \leq 1$. Using the threshold in Lemma 7, the proposition only applies to $q \geq \bar{q}$, when a cycling liberal-illiberal democracy occurs and the illiberal government's reelection probability is given by (51). Taking the derivative of (51) with respect to $q$

$$
\frac{\partial \operatorname{Pr}\left[m_{t}=1 \mid c^{*}\right]}{\partial q}=\left(\frac{\partial \operatorname{Pr}\left[s\left(\theta_{t}\right)=1\right]}{\partial q}+c^{*}(0) \frac{\partial \operatorname{Pr}\left[s\left(\theta_{t}\right)=0\right]}{\partial q}\right)+\operatorname{Pr}\left[s\left(\theta_{t}\right)=0\right] \frac{\partial c^{*}(0)}{\partial q} .
$$


Because

$$
\frac{\partial \operatorname{Pr}\left[s\left(\theta_{t}\right)=1\right]}{\partial q}=-\frac{\partial \operatorname{Pr}\left[s\left(\theta_{t}\right)=0\right]}{\partial q}=(2 \pi-1)
$$

the derivative simplifies to

$$
\frac{\partial \operatorname{Pr}\left[m_{t}=1 \mid c^{*}\right]}{\partial q}=(2 \pi-1)\left(1-c^{*}(0)\right)+\operatorname{Pr}\left[s\left(\theta_{t}\right)=0\right] \frac{\partial c^{*}(0)}{\partial q} \geq 0,
$$

where the inequality follows because, Proposition $7, \frac{\partial c^{*}(0)}{\partial q} \geq 0 \Longleftrightarrow \pi<\bar{L}$.

Now suppose that $\bar{L}<\pi<1 / 2$. Using the threshold in Lemma 8 , the reelection probability is equal to one for all $q \leq \hat{q}$ and equal to (51) otherwise. Thus, it suffices to show that (51) is decreasing with $q$ when $\bar{L}<\pi<1 / 2$ and $q>\hat{q}$-this follows from (52) by noting that, by Proposition $7, \frac{\partial c^{*}(0)}{\partial q} \geq 0 \Longleftrightarrow \pi<\bar{L}$.

It remains to show that if neither $\bar{L}<\pi<1 / 2$ nor $1 / 2<\pi<\bar{L}$ hold, then the reelection probability can be non-monotonic in $q$. We provide an explicit example that mirrors Panel (a) of Figure 3. Let $\bar{L}=1 / 3, \pi=0.32, \delta=0.9$. By Proposition 10, a cycling liberal-illiberal democracies occurs if

$$
\begin{aligned}
& \pi(1-\delta(1-\pi)(2 q-1))<\bar{L} \leq \operatorname{Pr}\left[\theta_{t}=1 \mid s\left(\theta_{t}\right)=1\right] \\
& \Longleftrightarrow \frac{1-\pi}{1+\pi}=\frac{17}{33} \leq q<1
\end{aligned}
$$

Therefore, when (53) holds, the derivative of illiberal government's reelection probability is equal to (52). For our parameter values, this is approximately

$$
-\frac{8.16 \times 10^{5}\left(2.60341-12.4286 q+12.6311 q^{2}\right)}{(-3836+7797 q)^{2}} .
$$

In the limit case of $q=1$, this value is negative and equal to -0.145933 . For $q=\frac{17}{33}$, this value is positive and equal to 11.1825 .

Proof of Proposition 9. Suppose $\zeta>0$ or $\gamma>0$. Let $\sigma^{*}$ be an equilibrium and recall that $g_{0}=\ell$ (and, hence, $c_{1}=c_{\ell}$ ). Let $\rho_{0}$ be the probability that the voter chooses $g_{t}=i$ when $c_{t}=c_{\ell}$, and let $\rho_{1} \geq \rho_{0}$ be the probability that the voter chooses $g_{t}=i$ when $c_{t}=c^{*} \cdot{ }^{35}$ If $g_{t}=i$, the illiberal government builds an autocracy with probability $\eta:=$ $1-(1-\zeta)(1-\gamma)>0$ and engages in censorship $c^{*}$ otherwise. Therefore, unless $\rho_{0}=0$ and conditional on not already being an autocracy, for any period $t$ and censorship policy $c_{t}$, the illiberal government builds an autocracy in period $t+1$ with probability at least

\footnotetext{
${ }^{35} \rho_{1} \geq \rho_{0}$ because, in equilibrium, it must be the case that $c^{*}$ guarantees the illiberal government at least as high probability of election as $c_{\ell}$; otherwise, there would be a profitable deviation-namely, $c_{t}=c_{\ell}$.
} 
$\rho_{0} \eta>0$, and the total probability that the illiberal government builds an autocracy by time $t$ is at least

$$
1-\left(1-\rho_{0} \eta\right)^{t}
$$

Therefore, either we have a stable liberal democracy if $\rho_{0}$, or the probability that the illiberal government builds an autocracy converges to 1 as $t \rightarrow \infty$.

In equilibrium, a stable liberal democracy occurs if and only if the voter never elects the illiberal government. Suppose $\sigma^{*}$ induces a stable liberal democracy. Then the accountability cost of illiberalism, $A\left(\pi, q, L, S, \delta, \zeta, \gamma \mid \sigma^{*}\right)$, is

$$
\frac{L-S \pi}{1-\delta}-(1-\gamma)(1-\zeta) \frac{L-S \pi}{1-\delta}=\frac{L-S \pi}{1-\delta}(1-(1-\gamma)(1-\zeta))
$$

and the voter's optimal strategy is

$$
g_{t}=i \quad \Longleftrightarrow \quad \mu_{t}^{*}\left(m_{t}, c_{t}\right) S \geq L+\delta \frac{L-S \pi}{1-\delta}(1-(1-\gamma)(1-\zeta)) .
$$

Therefore, a necessary condition for a stable liberal democracy is that (55) never holds for any $m_{t}$ and $c_{t}$. Because $\mu_{t}^{*}\left(m_{t}, c_{t}\right) \leq \mu_{t}^{*}\left(1, c_{\ell}\right)$ for all $c_{t}$, this condition is equivalent to

$$
\begin{aligned}
\mu_{t}^{*}\left(1, c_{\ell}\right) S & <L+\delta \frac{L-S \pi}{1-\delta}(1-(1-\gamma)(1-\zeta)) \\
\Longleftrightarrow L / S & >\frac{\mu_{t}^{*}\left(1, c_{\ell}\right)(1-\delta)+\delta \pi(1-(1-\gamma)(1-\zeta))}{1-\delta+\delta(1-(1-\gamma)(1-\zeta))} \\
& =: \bar{\kappa}^{\prime}(\pi, q, \delta ; \zeta, \gamma),
\end{aligned}
$$

which is strictly decreasing with $\gamma$ and $\zeta$.

We now show that (57) is a sufficient condition. Suppose that (57) holds and consider the assessment $\sigma^{\prime}=\left(g^{\prime}, c^{\prime},\left\{\mu_{t}^{*}\right\}_{t=1}^{\infty}\right)$ such that the voter' strategy $g^{\prime}$ satisfies (55) and $c^{\prime}$ is any censorship policy. Because (56) holds and voter's strategy, $g^{\prime}$, the voter never elects the illiberal government and, hence, we have a stable liberal democracy. Furthermore, the accountability cost of illiberalism is given by (54). Therefore, given $\sigma^{\prime}$, the voter's strategy is optimal. Furthermore, the illiberal government's choice of $c^{\prime}$ is also optimal, because (56) holds, the illiberal government is indifferent between any choice of censorship policy because they all induce a reelection probability of 0 . Finally, the voter's beliefs are derived using Bayes' rule. We conclude that $\sigma^{\prime}$ is an equilibrium, and (57) is a sufficient condition for a stable liberal democracy. 